\title{
Aid Under Fire: Development Projects and Civil Conflict*
}

\author{
Benjamin Crost \\ University of Colorado Denver \\ Joseph Felter \\ Stanford University \\ Patrick Johnston \\ RAND Corporation
}

October 9, 2012

\begin{abstract}
We estimate the causal effect of a large development program on conflict in the Philippines through a regression discontinuity design that exploits an arbitrary poverty threshold used to assign eligibility for the program. We find that barely eligible municipalities experienced a large increase in conflict casualties compared to barely ineligible ones. This increase is caused by insurgent-initiated incidents during the early stages of program-preparation. Our results are consistent with two mechanisms: that insurgents attempt to appropriate the program's resources by violent means or that they try to sabotage the program because its success would weaken their support in the population.
\end{abstract}

${ }^{*}$ The authors would like to thank Eli Berman, Michael Callen, Alexander B. Downes, Alain de Janvry, Jim Fearon, Julien Labonne, David D. Laitin, Ethan Ligon, Jeremy Magruder, Ted Miguel, Andrew Parker, Bob Powell, Elisabeth Sadoulet, Jacob N. Shapiro, Rob Wrobel, and participants of the NBER Summer Institute on the Economics of National Security for comments on earlier versions of the manuscript. Crost acknowledges financial support from the Institute of Business and Economic Research and the Center of Evaluation for Global Action at the University of California, Berkeley. Felter and Johnston acknowledge financial support from AFOSR Award \#FA9550-09-1-0314. Any opinions, findings, conclusions, and recommendations expressed in this publication are the authors' and do not necessarily reflect those of any other organization or entity. 


\section{Introduction}

Governments and international donors target large amounts of development aid to conflictaffected areas throughout the world. Despite this significant influx of resources, it remains unclear how aid affects conflict. The evidence is varied. Using fixed-effects approaches, Berman et al. (2011) and Iyengar et al. (2011) show that increases in spending on (laborintensive) reconstruction programs led to reductions in insurgent attacks in Iraq. Beath et al. (2011) present experimental evidence that aid has increased popular support for the government in Afghanistan, but no evidence that this has led to a decrease in insurgent attacks there. Indirect evidence for a possible positive effect of aid comes from Miguel et al. (2004) and Dube and Vargas (2011), who find that economic shocks - in the form of good rainfall and favorable world market prices for agricultural goods - caused a decrease in conflict in Africa and Colombia, respectively. On the other hand, Nunn and Qian (2012) find that U.S. food aid causes an increase in conflict in recipient countries.

This article enhances our understanding of the effect of development aid on conflict by estimating the causal effect of a large development program - the Philippines' Kapit-Bisig Laban sa Kahiripan - Comprehensive Integrated Delivery of Social Services (KALAHI-CIDSS) - on casualties in armed civil conflict. Financed by the World Bank with a budget of $\$ 180$ million, KALAHI-CIDSS was the Philippines' flagship anti-poverty program from 2003 through 2008. KALAHI-CIDSS is a community-driven development (CDD) program, a common type of development intervention and an increasingly popular tool for delivering aid in conflict-affected countries (Mansuri and Rao, 2004). Our empirical strategy is a regression discontinuity (RD) design, that exploits an arbitrary eligibility threshold for the program that restricted eligibility to the poorest 25 percent of municipalities in participating Philippine provinces. This eligibility threshold created a discontinuity in aid assignment, which allows us to identify its causal effect by comparing municipalities just above and just below the threshold. Our em-

pirical strategy allows us to overcome the problem of endogenous aid allocation and cleanly 
identify the causal effect of aid on conflict casualties. Data on this outcome were compiled from comprehensive information on conflict incidents involving the Armed Forces of the Philippines (AFP) between 2002 and 2009. The data were derived from the text of the AFP's original incident reports. It is similar to the US military's "Significant Activities" (SIGACTS) data, which has been used to advance the study of conflict based on the US experiences in Afghanistan and Iraq (Berman et al., 2011; Iyengar et al., 2011; Beath et al., 2011).

In contrast to much of the previous literature, we find that aid exacerbated violent conflict in this context. For the duration of this community-driven development program, municipalities that were barely eligible for the program suffered a large and statistically significant increase in violence compared to municipalities that were barely ineligible. We find no differences in pre- and post-program violence or other observable characteristics that could explain this effect. Further results show that most of the excess casualties occurred in the early stages of program preparation, in insurgent-initiated incidents, and that the bulk of casualties were suffered by government forces.

Our results are consistent with at least two possible mechanisms through which aid could increase conflict. The first is that an influx of aid will increase the amount of resources to be fought over, which in turn increases the incentive to fight. This mechanism has been described in a number of theoretical models (e.g. Hirshleifer, 1989; Grossman, 1991; Skaperdas, 1992; Dal Bo and Dal Bo, 2011). The second is that aid increases short-term conflict because it has the potential to weaken insurgents in the long-run, perhaps because it increases peaceful economic opportunities or popular support for the government. If insurgents expect a succesful aid program to weaken their position, they have an incentive to sabotage its implementation by violent means. ${ }^{1}$ We discuss the consistency of our evidence with these two mechanisms in Section 4.

\footnotetext{
${ }^{1}$ See Powell (2012) for a detailed theoretical account of how expected future shifts in power can lead to conflict.
} 


\subsection{Institutional Background: The KALAHI-CIDSS Program}

This paper studies the KALAHI-CIDSS program; a CDD program implemented by the Philippine government's Department of Social Welfare and Development and funded through World Bank loans. The program aims to enhance local infrastructure, governance, participation, and social cohesion. As of mid-2009, the end of our study period, more than 4000 villages in 184 municipalities across 40 provinces had received aid through KALAHI-CIDSS, making it the largest development program in the country during this period. ${ }^{2}$ Plans are currently being made to expand KALAHI-CIDSS, with the aim of doubling the number of recipient municipalities during the program's next phase. Figure 1 shows a map of the municipalities that received KALAHI-CIDSS aid during our period of observation.

Community-driven development programs are a common type of development intervention that has become a popular tool for delivering aid in conflict-affected countries. The World Bank lends more than two billion dollars annually for CDD projects (Mansuri and Rao 2004). Over the last decade, for example, CDD programs have been implemented in Afghanistan, Angola, Colombia, Indonesia, Nepal, Rwanda, and Sudan. KALAHI-CIDSS follows a standard CDD template. In the six months before the program begins, inhabitants of eligible municipalities are informed of the project and its procedures in a so-called "social preparation phase." Once the program officially begins, the participating municipalities receive a block grant for small-scale infrastructure projects. Each village within participating municipalities holds a series of meetings in which village members draft project proposals. Villages then send democratically elected representatives to participate in municipal-level inter-village fora, in which proposals are evaluated and funding is allocated. Proposals are funded until each municipality's grant has been exhausted. Once municipality funding has been allocated, community members are encouraged to monitor or participate in project implementation. ${ }^{3}$

\footnotetext{
${ }^{2}$ As of March 2010, there were 80 provinces and 1496 municipalities in the Philippines.

${ }^{3}$ See Parker (2005) for a detailed overview of the KALAHI-CIDSS process.
} 
The amount of aid distributed through KALAHI-CIDSS is substantial. Participating municipalities receive PhP300,000, or approximately $\$ 6000$, per village in their municipality. The average municipality has approximately 25 villages, making the average grant approximately $\$ 150,000$, or about $15 \%$ of an average municipality's annual budget. Over the course of the program, the project cycle is repeated three times-occasionally four-meaning that on average, participating municipalities receive a total of between $\$ 450,000$ and $\$ 600,000$ dollars.

\section{Empirical Strategy}

To estimate the causal effect of KALAHI-CIDSS on the intensity of violent conflict, we use a regression discontinuity $(\mathrm{RD})$ design. The $\mathrm{RD}$ design is made possible by an arbitrary eligibility threshold that was used to target the program. Targeting followed a two-staged approach. First, 42 eligible provinces were selected, among them were the 40 poorest in the country based on estimates from the Family Income and Expenditure Survey (FIES). The poverty levels of all municipalities within the eligible provinces were estimated using a poverty mapping methodology based on a combination of data from FIES and the 2000 Census of the Philippines (Balisacan et al., 2002; Balisacan and Edillon, 2003). The estimation was carried out by an independent consulting firm in order to make sure that it was based on objective criteria. In each eligible province, municipalities were ranked according to their poverty level and only the poorest quartile was eligible for KALAHI-CIDSS.

Each municipality's poverty score was calculated as a weighted combination of variables from the 2000 census and variables from a database on road conditions from the Department of Transportation. The road database is no longer available, so we are unable to replicate the

raw poverty scores and use them as the running variable of our RD design. Instead, we directly use the rankings published by Balisacan et al. (2002) and Balisacan and Edillon 
(2003) to generate the running variable, which is the distance of the municipality's poverty rank from the provincial eligibility threshold. Since only municipalities in the poorest quartile were eligible, the provincial threshold was calculated by dividing the number of municipalities in each province by four and then rounding to the nearest integer. ${ }^{4}$ This threshold number was then subtracted from the municipality's actual poverty rank to obtain its relative poverty rank. For each participating province, the richest eligible municipality has a relative poverty rank of zero and the poorest ineligible municipality has a relative poverty rank of one. Since the poverty ranking was used exclusively to target KALAHI-CIDSS and no other program, the only variable that should change discontinuously at this threshold is eligibility for KALAHI-CIDSS.

Our goal is to estimate the discontinuous change in conflict casualties across the eligibility threshold. Assuming that the unobserved variables are a smooth function of the running variable, this change reflects the causal effect of the KALAHI-CIDSS program. To ensure that our results are robust to different assumptions about the shape of this smooth function, we follow Ludwig and Miller (2007) and use two different specifications to obtain the RD estimator of the program's effect. The first is a regression that flexibly controls for quadratic trends on both sides of the threshold:

$$
Y_{i t}=\beta_{0}+\tau D_{i}+\beta_{1} X_{i}+\beta_{2} X_{i}^{2}+\beta_{3} D_{i} X_{i}+\beta_{4} D_{i} X_{i}^{2}+\alpha_{t}+\varepsilon_{i t}
$$

$Y_{i t}$ denotes the number of conflict casualties suffered by municipality $i$ in month $t . X_{i}$ denotes the municipality's relative poverty rank. $D_{i}$ is an indicator that takes the value 1 if the municipality is eligible for the program and 0 if it is not. The RD estimator is given by the parameter $\tau$.

\footnotetext{
${ }^{4}$ In cases where dividing a province's number of municipalities by 4 ended on .5 , the number of eligible municipalities was rounded down more often than up. We follow this approach and round down at .5, which improves the accuracy with which the relative poverty rank predicts participation in the program.
} 
The second specification is a nonparametric local linear regression. This approach estimates the following linear regression, while using kernel weights to give higher weight to observations that are closer to the threshold:

$$
Y_{i t}=\beta_{0}+\tau D_{i}+\beta_{1} X_{i}+\beta_{2} D_{i} X_{i}+\alpha_{t}+\varepsilon_{i t}
$$

Our baseline specification uses a triangular kernel with a bandwidth of 6 poverty ranks. Since there is currently no universally agreed-upon method for selecting the optimal bandwidth for local linear regressions, we follow Ludwig and Miller (2007) and also report results for a wide range of bandwidths between 1 and 6 ranks. The unit of observation is the municipalitymonth. Since our outcome of interest is a discrete "count" variable, we estimate both OLS and Poisson models. To deal with the potential serial and spatial correlation of conflict in our sample, the standard errors of all specifications are clustered at the province level.

When interpreting the results of this approach, it should be kept in mind that not all eligible municipalities participated in the program. Some municipalities declined to participate, and several others were dropped from the program by the implementing agency due to concerns about the security of its staff. Our results therefore constitute an "intention-totreat" effect - the effect of eligibility for the program regardless of later participation status. One might think that it would be preferable to estimate the local average treatment effect of program participation by "fuzzy" RD design that uses eligibility as an instrument for participation. However, we show in section 4 that a large part of the increase in violence occurred during the program's social preparation phase, which took place in all eligible municipalities, before it was clear whether they would actually participate in the program. Thus it appears that in many cases eligibility alone was sufficient to cause an increase in 
violence even in municipalities that did not ultimately participate in the program. ${ }^{5}$ This violates the exclusion restriction of the IV estimator; as a consequence, we only estimate the intention-to-treat effect.

\subsection{Timing of the Program}

Our goal is to estimate the effect of the KALAHI-CIDSS program on conflict during the period when the program was active as well as the pre-program and post-program periods. As mentioned in section 1.1, the first program activity was the social preparation phase, which took place in all eligible municipalities and began 6 months before the program was scheduled to start in participating municipalities. Overall, the scheduled duration of program activities was 3 years. We therefore define the program-period (including the social preparation phase) as lasting from 6 months before until 30 months after the program's scheduled start date. ${ }^{6}$

Our analysis is complicated somewhat by the fact that the program's implementing agency, DSWD, had a certain amount of leeway when choosing the program's start date in a municipality. This raises the concern that our results may be biased due to endogenous timing of the program. It is possible, for example, that DSWD scheduled eligible municipalities to receive the program at times when they were expected to have more (or less) conflict than usual. As a result, eligible municipalities would have more (or less) conflict during the program period than ineligible ones, even if the program had no effect on conflict. In order to ensure that this does not affect our results, our analysis only makes use of decisions about the start date that were made at the province level, before the municipality-level poverty rankings were calculated. At that time, DSWD did not yet know which municipalities would

\footnotetext{
${ }^{5}$ Anecdotal evidence suggests that some insurgent groups used violence to intimidate the population and keep the municipality from participating in the program (personal interview with DSWD director and senior project managers).

${ }^{6}$ We also separately estimate the program's effect during the social preparation phase and during the remaining program period.
} 
be eligible, so it could not have manipulated the program's schedule based on unobserved characteristics of eligible municipalities. $^{7}$

To describe our empirical approach, it is necessary to review the program's timeline in some detail. KALAHI-CIDSS was rolled out in 5 phases, the start dates of which are shown in Table 1. The phases did not differ in any way except for their start dates. The assignment of municipalities to phases was made in two steps. In 2002 - before the poverty ranking was calculated - the participating provinces were divided into two groups, which we call Batch A and Batch B. All municipalities in Batch A provinces were covered in Phase 2 of the program, whose scheduled start date was June $2003 .{ }^{8}$ Since provinces were assigned to batches before eligibility was determined, endogenous timing is not an issue for municipalities in Batch A.

Municipalities in Batch B provinces were covered in Phases 3A, 3B and 4. Municipalities in Batch B were assigned to phases after eligibility was determined. Thus, endogenous timing is a potential problem, since DSWD might have assigned municipalities to phases based on unobserved information about how much conflict they would experience at a given time. To address this concern, we define the program's start date for all municipalities in Batch B provinces to be the start date of the largest of the three phases, Phase 4, which began in August 2006. This approach ensures that the start date used in our analysis only depends on the assignment of provinces to batches, which was determined before DSWD knew which municipalities would be eligible. Thus, eligible and ineligible municipalities should not differ in unobserved characteristics at the start date. By assigning the same start date to all municipalities in the same province, our estimator is based on comparing eligible and ineligible municipalities in the same province during the same time period. To make sure that our results are not driven by the way we deal with endogenous timing, we conduct two robustness tests, the results of which are reported in the appendix. First, we present

\footnotetext{
${ }^{7}$ The poverty ranking was calculated by an independent consulting firm so that DSWD did not know in advance which municipalities would be eligible for the program.

${ }^{8}$ Phase 1 was a pilot phase, for which municipalities were chosen independently of the poverty ranking, so that it is not relevant for our analysis.
} 
estimates based only on the subsample of municipalities in Batch A provinces, for which endogenous timing is not an issue. Second, we implement an alternative method for choosing the start date for Batch B, in which we weight observations by the ex-ante probability with which municipalities were covered by the program at the time of the observation. ${ }^{9}$

\subsection{Robustness Tests}

We conduct several robustness tests to evaluate the validity of the RD estimator. The first concern is that DSWD manipulated the poverty ranking, to target the program towards certain municipalities. As a test for this, we estimate whether eligible and ineligible municipalities differed in observable characteristics before the start of the program. If the assumptions of the RD estimator hold, we should not observe a systematic change in observable (and unobservable) pre-program characteristics at the eligibility threshold. In addition, the appendix reports placebo tests for discontinuities in post-treatment variables that are unlikely to have been affected by the program. A second concern is that DSWD had advance knowledge of the outcome of the poverty ranking and used this knowledge to manipulate the timing of the program. As a robustness test for this, we estimate the program's "effect" on conflict in the 12 months leading up to the start of the social preparation phase. If DSWD had manipulated start dates in order to target the program to municipalities with more (or less) conflict, we would expect eligible and ineligible municipalities to have systematically different levels of conflict even before the program began. The results of both of these tests are reported in Section 4. As a third robustness test, we examine whether there are discontinuities in conflict at other "pseudo-thresholds" where eligibility for the program did

\footnotetext{
${ }^{9}$ Out of the 117 municipalities that were covered in Batch B, 34 were covered in Phase 3A, 29 in Phase $3 \mathrm{~B}$ and the remaining 54 in Phase 4 . We therefore assigned a weight of $\frac{34}{117}$ to municipalities during the program period of Phase 3A, which started in October 2004, a weight of $\frac{29}{117}$ to observations during the period of Phase, which started in January 2006, and a weight of $\frac{54}{117}$ to observations in the program period of Phase 4, which started in August 2006. Observations outside of the program period of any phase receive a weight of zero. For observations that fall into the program period of several phases the weights were assigned additively. For example, observations in March 2006, when Phases 3A and 3B were both active, receive a weight of $\frac{34+29}{117}$. The results of this test are reported in the appendix.
} 
not change, which might occur if our results were due to mis-specification of the relationship between running variable and outcome. The results of these tests are reported in the appendix. $^{10}$

\section{Data}

The data on civil conflict and violence used in this paper come from the Armed Forces of the Philippines' (AFP) records of civil conflict-related incidents. The data were derived from the original incident reports of AFP units operating throughout the Philippines from 2002 through 2009. The incident-level data are similar to the US military's SIGACTS data, which have been used to study the conflicts in Afghanistan and Iraq (Berman et al., 2011; Iyengar et al., 2011; Beath et al., 2011). The dataset contains information on the date, location, the insurgent group involved, the initiating party, and the total number of casualties suffered by government troops, insurgents, and civilians (see Felter 2005). The data are comprehensive, covering every conflict-related incident reported to the AFP's Joint Operations Center (JOC) by units deployed across the country. In total, the database documents more than 21,000 unique incidents during this period, which led to just under 10,000 casualties. The depth, breadth, and overall quality of the AFP's database makes it a unique resource for conflict researchers.

One concern about the data is that AFP troops may selectively report the number of casualties that they experience. While this should be kept in mind when interpreting the results, we believe that the extent of misreporting is limited. First, the original field reports our data is coded from are for internal use by the Armed Forces of the Philippines and the AFP's

\footnotetext{
${ }^{10}$ One disadvantage of our design is that we cannot use the density of the running variable to test for possible manipulations of the poverty ranking. Since there are as many municipalities that are one rank below the eligibility cutoff as there are one rank above it, the density of the running variable is smooth by construction. It is therefore impossible to detect manipulations by testing for "bunching" of municipalities at the threshold.
} 
chain of command has a strong incentive to enforce accurate reporting. The reports sent to the JOC are collected in part to develop intelligence assessments and plan future AFP operations. Inaccurate information included in field reports might jeopardize future military operations and put the lives of AFP troops at risk. Concerns about misreporting should be further limited by the fact that we focus on casualties as the outcome of interest. ${ }^{11}$ Casualties are relatively easy to verify, which limits the likelihood that AFP units misreport casualties, even if they had an incentive to do so. ${ }^{12}$ Moreover, tests reported in section 4 indicate that our results are largely driven by an increase in government casualties, which are the easiest outcome to verify by the JOC. The information on which party initiated the incident, which we use to distinguish between government-initiated and insurgent-initiated violence can in some cases be subjectively interpreted and is more likely to be prone to misreporting. However, previous studies make similar distinctions based on comparable data reported by US military units in the SIGACTS data (e.g. Berman et al., 2011; Iyengar et al., 2011; Beath et al., 2011) and we follow this approach to ensure that our results are comparable with those of the literature.

The second concern is that eligible municipalities may experience more casualties simply because more AFP troops are present to engage in conflict with insurgents. It is, for example, possible that the AFP moved its troops towards eligible municipalities to enhance the security of the program. If this was the case, the program may not have increased aggregate conflict in the country as a whole, but merely shifted it from one location to another by acting as a "conflict magnet." To address this concern, we estimate the program's spillover effect on conflict in nearby municipalities. If the program's effect was mainly due to troop movements,

\footnotetext{
${ }^{11}$ We find the same qualitative results when using raw incident counts as the outcome of interest, though the point estimates are slightly smaller and less precisely estimated.

${ }^{12}$ Note, however, that using data from newspaper reports, Arcand et al. (2010) find that the KALAHICIDSS program caused a decrease in casualties, at least for one of the conflicts in the Philippines. However, their data contains a much smaller number of incidents and likely has more missing data than ours. For example, they report an average of only 0.42 incidents per year within a $100 \mathrm{~km}$ radius around each municipality (given the dense population of the Philippines, a 100km radius contains on average over 35 other municipalities). The precision of our data allows us to more accurately map casualties to municipalities.
} 
we would expect conflict to decrease in the municipalities that the troops were moved from, which are likely to be nearby. The results of this analysis are presented in Section 4.9 and show no evidence of a spillover effect.

\section{Results}

\subsection{Summary Statistics}

Table 2 reports summary statistics of conflict outcomes and control variables in our sample of municipalities within 6 ranks of the eligibility threshold for the KALAHI-CIDSS program. The statistics show that the conflict is of relatively low-intensity, with approximately 0.078 casualties per municipality per month, or 0.94 casualties per municipality per year. The majority of the casualties are suffered by government forces and occur as a result of incidents initiated by insurgents. Out of the three main insurgent groups, incidents involving the communist New People's Army (NPA) account for the vast majority of casualties. The conflict with the Muslim-separatist Moro-Islamic Liberation Front (MILF) has a smaller geographic reach (the MILF is only active in parts of the southern island of Mindanao and the Sulu Sea), and therefore accounts for a smaller fraction of total casualties. The third group, referred to in the AFP data as "Lawless Elements", is comprised by organized criminal groups without clearly defined political goals. These groups also account for only a small fraction of total casualties. As expected, based on the program's eligibility criteria, the summary statistics of the control variables show that municipalities in the sample are relatively poor. For example, in the average municipality less than $40 \%$ of households have access to electricity and only approximately $50 \%$ have access to indoor plumbing. 


\subsection{Eligibility and Participation}

Figure 2 plots the observed probability of participating in KALAHI-CIDSS against the relative poverty rank. As in all of the graphs that follow, the scatter dots represent average values for bins with a width of 2 poverty ranks. The vertical bars are $95 \%$ confidence intervals. The size of the scatter dot represents the number of municipalities within the bin. The dashed line represents a quadratic fit to the data and the solid line presents a local linear fit with a triangular kernel and a bandwidth of 6 . The graph shows that the probability of participation decreases sharply at the eligibility threshold, though some eligible municipalities did not participate and were replaced by municipalities above the threshold. As discussed in section 2, participation in the program is potentially endogenous to the conflict, since several municipalities did not participate due to security concerns. Our empirical analysis therefore estimates the "intention to treat" effect - the effect of eligibility regardless of later participation status. Table 3 shows the results of RD regressions of the effect of eligibility on participation. The results show that the probability of participation increased significantly at the eligibility threshold, by between 28 and 47 percentage points.

\subsection{The Effect of KALAHI-CIDSS on Conflict Casualties}

Figure 3 graphically displays the relationship between conflict casualties and the relative poverty rank. The top left panel shows the relationship for the entire duration of the program. The graph shows that barely eligible municipalities - the ones whose poverty ranks put them just below the eligibility threshold - suffered more total casualties than barely ineligible municipalities, which suggests that the program had a causal effect on casualties. The graph also shows that for eligible municipalities, casualties decreased with distance to the threshold. This raises the possibility that the program's effect may not be the same for all eligible municipalities. A look at the graphs of control variables in Figure 4 shows that 
municipalities further away from the threshold have smaller populations, less highway access, and are less fractionalized ethnically and religiously. Possible explanations for the trend are therefore that the program's effect is proportional to population and/or that the program only increases conflict in fractionalized municipalities, where there is a higher potential for disagreement (of course it is also possible that municipalities further from the threshold differ in unobserved variables that explain the trend).

Panel A of Table 4 presents the corresponding regression results from the estimating equations in Section 2. The table shows that the program has a significant positive (in sign) effect on total casualties during the 3 years after the program's start. Depending on the specification, the effect size ranges between 0.071 and 0.11 casualties per month, which corresponds to between 0.95 and 1.32 casualties per year. This effect is large relative to the average level of conflict casualties in the sample of approximately 0.078 per month or 0.94 per year. If we assumed the effect was constant across all 184 municipalities that received the program, the program would have caused between 470 and 720 excess casualties during the 3 years in which it was active.

\subsection{Timing of the Violence}

We now analyze the timing of the program's effect on violence. For this, we separately analyze the effect of eligibility on casualties during three time-periods: the pre-program period, the social preparation phase and the remaining program period. The social preparation phase took place in the 6 months before the scheduled start of the program. During this phase, the program was introduced to the population in eligible municipalities and municipal officials were required to sign a memorandum of understanding to allow the program's implementation. The pre-program phase is defined as the 12 months before the start of the social preparation phase (i.e. from 18 months to 7 months before the program's scheduled start). 
The remaining program period is defined as the 30 months after the program's scheduled start.

The results in Figure 3 and Table 4 show that the program's effect is concentrated in the social preparation phase. During this period, eligible municipalities experienced between 0.25 and 0.39 excess casualties per month. By contrast, the program's estimated effect during the remaining program period was between 5 and 10 times smaller and not statistically significant in most specifications. These findings are consistent with the hypothesis that insurgents attacked eligible municipalities in order to sabotage the program. This would have been easiest during the social preparation phase, when municipalities had not yet decided whether to actually participate in the program (in fact, several municipalities opted out or were dropped from the program at this stage by DSWD due to concerns about the security situation). The findings are perhaps less easy to explain with the hypothesis that insurgents tried to appropriate the program's resources, since funds were not disbursed until the beginning of the program. However, it is possible that insurgents tried to extort payments from municipal officials in return for allowing the program proceed, and launched attacks during the social preparation phase in order to make their threats credible, so a variant of this mechanism cannot be ruled out.

The estimates of the program's "effect" during the pre-program phase serve as a robustness tests for possible violations of the RD assumptions. Here, the concern is that the poverty ranking or the timing of the rollout was manipulated in order to give the program to municipalities that were more (or less) heavily affected by conflict. If this were the case, we would expect eligible municipalities to have significantly more (or fewer) casualties even before the program becomes active. The results in Panel B of Table 4 show no evidence of this. Barely eligible and barely ineligible municipalities experienced almost exactly the same number of casualties in the pre-program period and the difference is not statistically 
significant. This increases our confidence that the poverty ranking was not manipulated and that the assumptions of the RD estimator hold.

\subsection{Balance Tests}

Table 5 shows the results of a series of robustness tests for smoothness of pre-treatment observable variables across the threshold. These tests estimate the same equations used to estimate the program's effect on casualties, but use a number of control variables as the dependent variable. The parameter associated with eligibility reflects the discontinuous change in the control variables across the eligibility threshold. Under the identifying assumption of the RD estimator - that assignment close to the threshold is as good as random - the control variables should not change systematically across the threshold. The results in Figure 4 and Table 5 are consistent with this assumption. The "effect" of eligibility is not statistically significant for any of the control variables, which suggests that the variables did not differ systematically across the eligibility threshold. ${ }^{13}$

\subsection{Robustness to Choice of Bandwidth}

As mentioned in Section 2, there is currently no widely agreed-upon method for selecting the optimal bandwidth for local linear regressions. We therefore follow Ludwig and Miller (2007) and report results for a wide range of bandwidths. Table 6 shows that the estimates of the program's effect on total casualties in the entire program period and the social preparation

\footnotetext{
${ }^{13}$ We conducted two additional robustness tests and report their results in the appendix. First, we estimated the change across the threshold in an outcome that we do not expect to be affected by the program - the 2003 poverty rate - and found no evidence of a discontinuity. Second, we tested for discontinuities in casualties at values of the running variable away from the threshold. Finding discontinuities at those "pseudo-thresholds", where eligibility does not change, would raise the concern that our results are due to mis-specified non-linearities in the relationship between the running variable and the outcome Imbens and Lemieux (2008). Following Imbens and Lemieux's recommendation, we tested for discontinuities at the medians of the running variable for eligible and ineligible municipalities, located at -2 and 3 relative poverty ranks, respectively. We found no evidence for a statistically significant change in the outcome across these thresholds. These results are reported in the Appendix.
} 
phase is positive and statistically significant (at least at the $10 \%$ level) for all bandwidths between 1 and 6 ranks. ${ }^{14}$ The estimates for the entire program period range between 0.07 and 0.10 , while the estimates for the social preparation phase range between 0.27 and 0.50 . The estimated effect on casualties in the pre-program phase and the remaining program phase (not including the social preparation phase) are not statistically significant for any of the bandwidths. Overall, the robustness test increases our confidence that our results are not dependent on the choice of a particular bandwidth for the RD design.

\subsection{Who Suffers the Casualties?}

The top two panels in Figure 5 suggest that the discontinuous change across the eligibility threshold is particularly strong for casualties in insurgent-initiated incidents, and much less pronounced for casualties in government-initiated incidents. The corresponding results in Table 7 supports this conclusion. The program's effect is mainly due to its effect on casualties in insurgent-initiated incidents, which ranges between 0.050 and 0.086 and is statistically significant in all specifications. The program's estimated effect on casualties in governmentinitiated incidents is between 3 and 5 times smaller and not statistically significant in any of the specifications. This result is consistent with the hypothesis that the program increased the insurgents' incentive for violence, but did not substantially affect the incentives of government forces.

In addition, the bottom three panels in Figure 5 and the corresponding results in Table 7 show that the program's effect is mostly due to its effect on casualties suffered by government forces, who suffer between 0.043 and 0.090 excess casualties per month due to the program. The effect on insurgent casualties is between 5 and 10 times smaller and not statistically significant in any of the specifications. For civilian casualties, the point estimate of the program's effect ranges between 0.008 and 0.012 , which is large relative to the mean of civilian

\footnotetext{
${ }^{14} 85 \%$ of eligible municipalities are within a bandwidth of 6 ranks from the threshold.
} 
casualties of approximately 0.017 , though the estimates are not statistically significant in the quadratic models. ${ }^{15}$

\subsection{Which Conflicts are Affected?}

We now separately analyze the program's effect on the conflict with two of the Philippines' main insurgent groups: the communist New People's Army (NPA), the Muslim-separatist Moro-Islamic Liberation Front (MILF). In addition, we analyze the program's effect on conflict with so-called "lawless elements", a term used to describe organized criminal groups without a clearly defined political agenda. Since the three groups have different motives, it is possible that their responses to the program differed.

Figure 6 graphically presents the relationship between poverty rank and casualties in incidents that involve each of these three groups. The corresponding regression results in Table 8 show that the program caused an increase in the intensity of the conflicts with NPA and MILF. The effect on conflict with the NPA is estimated between 0.047 and 0.094 . The estimated effect on conflict with the MILF is somewhat smaller in absolute value, ranging between 0.020 and 0.031 , and not statistically significant in all specifications. However, the point estimates are very large compared to the lower sample mean of 0.010 . The table also shows that the program did not increase effect on conflict with lawless elements. If anything this conflict was less intense in eligible municipalities, though the difference is not statistically significant in all specifications. This finding suggests that the program only affected conflict with politically motivated groups. It is consistent with the hypothesis that politically motivated insurgents try to sabotage the program because its success would weaken their support

\footnotetext{
${ }^{15}$ The finding that the effect is mostly due to an increase in government casualties alleviates potential concerns about misreporting of casualties. Of all types of casualties, government casualties are the easiest to verify by the AFP, which has a strong incentive to maintain accountability of its personnel and to ensure the data's accuracy for its internal use. Therefore, government casualties are the least likely type to be misreported when the AFP units submit field reports. The result is also consistent with the finding that most of the casualties occur in insurgent-initiated incidents, since a common pattern in many conflicts is that the side with the initiative suffers substantially fewer casualties than the side that is being attacked.
} 
in the population. The finding is less easy to explain with the hypothesis that the program increases conflict by increasing the amount of resources to be fought over. If this were the case, we would expect the more criminally motivated lawless elements to have an equally large incentive to appropriate resources as the politically motivated insurgencies. It is also possible, however, that lawless elements had a similar incentive to attack the program but lacked the capacity to do so. Another explanation is that AFP troops in KALAHI-CIDSS municipalities perceived attacks as more politically motivated and were therefore less likely to classify attackers as lawless elements.

\subsection{Are There Spillovers to Nearby Municipalities?}

As mentioned in Section 3, a potential concern is that troop movements between municipalities are driving our results. It is possible, for example, that the AFP moved its troops towards municipalities that were eligible for KALAHI-CIDSS, perhaps because the military sought to enhance the security of the program, and that as a result, eligible municipalities experienced more casualties simply because more AFP troops were present to engage in conflict. It is therefore possible that the program did not increase aggregate conflict in the country as a whole, but merely shifted conflict from one location to another by acting as a "conflict magnet".

To test for evidence of this, we analyzed the program's effect on casualties in municipalities that were close to eligible municipalities but not necessarily eligible themselves. ${ }^{16}$ To do this, we estimated regressions whose dependent variable is the average number of casualties in municipalities within a certain radius of a municipality in our sample (not including casualties in the sample municipality itself.) If there were spillover effects due to troop

\footnotetext{
${ }^{16}$ The Philippine military assigns units by geographic Areas of Responsibility (AOR). Therefore, if additional units were deployed to eligible municipalities, they would have most likely been moved from nearby municipalities in the same AOR.
} 
movement, we would expect the program to have a negative effect on the number of casualties in municipalities close to an eligible municipality.

Figure 7 and Table 9 show that we cannot find evidence of such a spillover effect. The point estimates of the program's effect on casualties within 10-40 kilometers are negative but not statistically significant. In addition, Panel B of Table 9 and the bottom panel of Figure 7 show that there were already fewer casualties close to eligible municipalities in the pre-program period. The program's estimated spillover "effect" in the pre-program period is of a similar size as the estimated effect during the program period. Thus, the program does not appear to have had any substantial effect on conflict close to, but outside of, eligible municipalities.

\section{Conclusion}

Governments and international donors continue to target large amounts of development aid to areas affected by civil conflict, some of it in the hope that aid will reduce conflict by weakening popular support for insurgent movements. This paper presents evidence that development aid can have the unintended effect of increasing conflict, at least in the short term. Our estimates show that eligibility for a large-scale community-driven development program - the Philippine's KALAHI-CIDSS - caused a large and statistically significant increase in conflict casualties. The program's effect was strongest in its early stages. The majority of the casualties were suffered by government troops and civilians and in incidents initiated by insurgents.

One possible explanation for these findings is that insurgents try to sabotage the program because they anticipate that its success will strengthen popular support for the government and thereby weaken their position. This explanation is consistent with the finding of Beath

et al. (2011) that a successful community-driven development increased support for the 
government in Afghanistan. It might be precisely this positive (from the government's point of view) effect of CDD projects that leads insurgents to attack the projects and thereby exacerbate violence in the short-term. This explanation is consistent with our finding that the program's effect is largest during the social preparation phase, when it is still possible to keep municipalities from participating in the program. Another possible explanation for the increase in conflict is that insurgents attempt to extort payments from municipal officials in return for letting the program proceed, and launch attacks during the social preparation phase in order to make their threats credible.

Our findings differ from the earlier results of Berman et al. (2011), who found that development projects funded by the US Army led to a decrease in violence in Iraq under certain conditions. A possible explanation for this difference in results is that the projects found to be violence reducing by Berman et al. (2011) were relatively small and implemented by the US Army as a complement to small unit counterinsurgency operations. Insurgents may therefore have had little opportunity to anticipate the projects and develop plans to interfere with them, which would explain why they did not cause an increase in violence. The projects funded by KALAHI-CIDSS, in contrast, were larger in scale and had longer lags between announcement and actual project implementation. Additionaly, KALAHI-CIDSS was implemented by a civilian agency and not directly coordinated with increased security efforts. Insurgents may therefore have had greater opportunities to sabotage the program or appropriate its resources, which would explain its conflict-increasing effect.

\section{References}

Arcand, Jean-Louis, Adama Bah, and Julien Labonne, "Conflict, Ideology and Foreign Aid," Mimeo, 2010.

Balisacan, Arsenio M. and Rosemarie G. Edillon, "Second Poverty Mapping and 
Targeting Study for Phases III and IV of KALAHI-CIDSS," Technical Report, Asia-Pacific Policy Center October 2003.

_, _, and Geoffrey M. Ducanes, "Poverty Mapping and Targeting for KALAHICIDSS," Technical Report, Asia-Pacific Policy Center December 2002.

Beath, Andrew, Fotini Christia, and Ruben Enikolopov, "Winning Hearts and Minds through Development Aid: Evidence from a Field Experiment in Afghanistan," Centre for Economic and Financial Research at New Economic School Working Paper No 166, October 2011.

Berman, Eli, Jacob N. Shapiro, and Joseph H. Felter, "Can Hearts and Minds Be Bought? The Economics of Counterinsurgency in Iraq," Journal of Political Economy, August 2011, 119 (4), 766-819.

Bo, Ernesto Dal and Pedro Dal Bo, "Workers, Warriors and Criminals: Social Conflict in General Equlibrium," Journal of the European Economic Association, 2011, 9 (4), 646677.

Dube, Oeindrila and Juan Vargas, "Commodity Price Shocks and Civil Conflict: Evidence from Colombia," Unpublished Working Paper, 2011.

Felter, Joseph H., "Bringing Guns to a Knife Fight: A Case for Empirical Study of Counterinsurgency." PhD dissertation, Stanford University, Stanford, CA 2005.

Grossman, Herschel I., "A General Equlibrium Model of Insurrections," American Economic Review, 1991, 81 (4), 912-921.

Hirshleifer, Jack, "Conflict and Rent-Seeking Success Functions: Ratio vs. Difference Models of Relative Success," Public Choice, 1989, 63 (2), 101-112.

Imbens, Guido W. and Thomas Lemieux, "Regression discontinuity designs: A guide to practice," Journal of Econometrics, 2008, 142 (2), 615-635. 
Iyengar, Radha, Jonathan Monten, and Matthew Hanson, "Building Peace: The Impact of Aid on the Labor Market for Insurgents," NBER Working Paper, 2011.

Ludwig, Jens and Douglas I. Miller, "Does head Start Improve Children's Life Chances? Evidence from a Regression Discontinuity Design," Quarterly Journal of Economics, 2007, 122 (1), 159-208.

Mansuri, Ghazala and Vijayendra Rao, "Community-Based and -Driven Development: A Critical Review," The World Bank Research Observer, Spring 2004, 19 (1), 1-39.

Miguel, Edward, Shanker Satyanath, and Ernest Sergenti, "Economic Shocks and Civil Conflict: An Instrumental Variables Approach," The Journal of Political Economy, August 2004, $112(4), 725-753$.

Nunn, Nathan and Nancy Qian, "Aiding Conflict: The Impact of U.S. Food Aid on Civil War," NBER Working Paper, 2012, 17794.

Parker, Andrew, Empowering the Poor: The KALAHI-CIDSS Community-Driven Development Project, Washington, DC: World Bank, 2005.

Powell, Robert, "Persistent Fighting and Shifting Power," American Journal of Political Science, 2012, 56 (3), 620-637.

Skaperdas, Stergios, "Cooperation, Conflict, and Power in the Absence of Property Rights," American Economic Review, 1992, 82 (4), 720-739. 


\section{Tables and Figures}


Table 1: Timetable of KALAHI-CIDSS Phases

\begin{tabular}{|c|c|c|c|c|}
\hline \hline Province Batch & Phase & Start date & Municipalities & Villages \\
\hline Pilot & I & January 2003 & 11 & 201 \\
\hline A & II & June 2003 & 56 & 1291 \\
\hline B & III A & October 2004 & 34 & 883 \\
\hline B & III B & January 2006 & 29 & 727 \\
\hline B & IV & August 2006 & 54 & 1127 \\
\hline
\end{tabular}

Source: Department of Social Welfare and Development. 
Table 2: Summary Statistics

\begin{tabular}{lcc}
\hline \hline & Mean & Std. Deviation \\
\hline Outcome Variables & & \\
\hline Total casualties (/month) & 0.0782 & 0.689 \\
Insurgent casualties & 0.0238 & 0.404 \\
Government casualties & 0.0403 & 0.414 \\
Civilian casualties & 0.0168 & 0.273 \\
Casualties in insurgent-initiated incidents & 0.0444 & 0.526 \\
Casualties in government-initiated incidents & 0.0334 & 0.423 \\
Casualties in incidents involving the NPA & 0.0551 & 0.514 \\
Casualties in incidents involving the MILF & 0.0106 & 0.386 \\
Casualties in incidents involving "Lawless Elements" & 0.0103 & 0.203 \\
\hline Control Variables & & \\
\hline Population & 29687 & 19391 \\
Fraction of villages with highway access & 0.684 & 0.294 \\
Ethnic fractionalization index & 0.285 & 0.278 \\
Religious fractionalization index & 0.292 & 0.228 \\
Muslim population fraction & 0.034 & 0.131 \\
Affected by insurgents & 0.419 & 0.494 \\
Frac. of HH with access to electricity & 0.387 & 0.172 \\
Frac. of HH with access to indoor plumbing & 0.518 & 0.195 \\
\hline Observations & 38299 & 38299 \\
Municipalities & 399 & 399 \\
\hline \hline
\end{tabular}

The table reports summary statistics of monthly conflict casualties reported by units of the Armed Forces of the Philippines' (AFP) in the period 2002-2009. The sample is restricted to municipalities within 6 poverty ranks of the provincial eligibility threshold for the KALAHI-CIDSS program. 
Table 3: Effect of Eligibility on Participation

\begin{tabular}{|c|c|c|c|c|c|c|c|c|}
\hline \multirow[b]{3}{*}{ Eligible } & \multicolumn{8}{|c|}{ "Dependent variable: participation in KALAHI-CIDSS } \\
\hline & \multicolumn{2}{|c|}{ Local Linear } & \multicolumn{2}{|c|}{ Quadratic } & \multicolumn{2}{|c|}{ Local Linear } & \multicolumn{2}{|c|}{ Quadratic } \\
\hline & $\begin{array}{c}0.416^{* * *} \\
(0.100)\end{array}$ & $\begin{array}{c}0.429^{* * *} \\
(0.098)\end{array}$ & $\begin{array}{c}0.278^{*} \\
(0.162)\end{array}$ & $\begin{array}{c}0.293^{*} \\
(0.166)\end{array}$ & $\begin{array}{c}0.474^{* * *} \\
(0.0805)\end{array}$ & $\begin{array}{c}0.471^{* * *} \\
(0.0809)\end{array}$ & $\begin{array}{c}0.358^{* * *} \\
(0.128)\end{array}$ & $\begin{array}{c}0.362^{* * *} \\
(0.131)\end{array}$ \\
\hline Controls & No & Yes & No & Yes & No & Yes & No & Yes \\
\hline Observations & 399 & 399 & 399 & 399 & 399 & 399 & 399 & 399 \\
\hline
\end{tabular}

The table reports results of the Regression Discontinuity design described in Section 2. The running variable is the distance between the municipality's poverty rank and the provinical eligibility threshold. Local linear regressions control for flexible trends of the running variable on each side of the eligibility threshold and use triangular kernel weights with a bandwidth of 6 ranks. Quadratic regressions control for flexible quadratic trends of the running variable on both sides of the threshold. For probit models, reported values are marginal effects. ${ }^{*},{ }^{* * * *}$ denote statistical significance of the underlying coefficient at the $10 \%, 5 \%$ and $1 \%$ levels. Control variables are shown in Table 2. Standard errors are clustered at the province level. 
Table 4: The Effect of Eligibility for KALAHI-CIDSS on Conflict Casualties

\begin{tabular}{|c|c|c|c|c|c|c|c|c|}
\hline & \multicolumn{4}{|c|}{ Poisson QMLE } & \multicolumn{4}{|c|}{$\overline{\mathrm{OLS}}$} \\
\hline & \multicolumn{2}{|c|}{ Local Linear } & \multicolumn{2}{|c|}{ Quadratic } & \multicolumn{2}{|c|}{ Local Linear } & \multicolumn{2}{|c|}{ Quadratic } \\
\hline & (1) & $(2)$ & $(3)$ & $(4)$ & $(5)$ & $(6)$ & $(7)$ & $(8)$ \\
\hline \multicolumn{9}{|c|}{ Panel A: Entire program period (14364 municipality-month observations) } \\
\hline Eligible & $\begin{array}{c}0.0733^{* * *} \\
(0.0269)\end{array}$ & $\begin{array}{c}0.0712^{* * *} \\
(0.0235)\end{array}$ & $\begin{array}{c}0.0961^{* * *} \\
(0.0348)\end{array}$ & $\begin{array}{c}0.101^{* * *} \\
(0.0292)\end{array}$ & $\begin{array}{c}0.0784^{* *} \\
(0.0298)\end{array}$ & $\begin{array}{c}0.0729^{* *} \\
(0.0280)\end{array}$ & $\begin{array}{l}0.109^{* *} \\
(0.0441)\end{array}$ & $\begin{array}{c}0.110^{* * *} \\
(0.0403)\end{array}$ \\
\hline \multicolumn{9}{|c|}{ Panel B: Pre-program period (4788 municipality-month observations) } \\
\hline Eligible & $\begin{array}{c}0.0033 \\
(0.0404)\end{array}$ & $\begin{array}{l}-0.0050 \\
(0.0340)\end{array}$ & $\begin{array}{c}0.0049 \\
(0.0439)\end{array}$ & $\begin{array}{c}-0.0031 \\
(0.0398)\end{array}$ & $\begin{array}{c}0.0027 \\
(0.0544)\end{array}$ & $\begin{array}{c}0.0066 \\
(0.0467)\end{array}$ & $\begin{array}{c}0.0047 \\
(0.0685)\end{array}$ & $\begin{array}{c}0.0094 \\
(0.0660)\end{array}$ \\
\hline \multicolumn{9}{|c|}{ Panel C: Social preparation phase (2394 municipality-month observations) } \\
\hline Eligible & $\begin{array}{c}0.252^{* * *} \\
(0.120)\end{array}$ & $\begin{array}{c}0.270^{* * *} \\
(0.102)\end{array}$ & $\begin{array}{c}0.283^{* *} \\
(0.135)\end{array}$ & $\begin{array}{c}0.304^{* *} \\
(0.131)\end{array}$ & $\begin{array}{c}0.252^{* *} \\
(0.131)\end{array}$ & $\begin{array}{c}0.277^{* *} \\
(0.121)\end{array}$ & $\begin{array}{l}0.365^{*} \\
(0.188)\end{array}$ & $\begin{array}{c}0.390^{* *} \\
(0.179)\end{array}$ \\
\hline \multicolumn{9}{|c|}{ Panel D: Rest of program period (11970 municipality-month observations) } \\
\hline Eligible & $\begin{array}{c}0.0367 \\
(0.0265)\end{array}$ & $\begin{array}{c}0.0285 \\
(0.0260)\end{array}$ & $\begin{array}{c}0.0375 \\
(0.0280)\end{array}$ & $\begin{array}{c}0.0268 \\
(0.0277)\end{array}$ & $\begin{array}{l}0.0598^{*} \\
(0.0326)\end{array}$ & $\begin{array}{c}0.0575^{* *} \\
(0.0297)\end{array}$ & $\begin{array}{l}0.0660^{*} \\
(0.0372)\end{array}$ & $\begin{array}{c}0.0536 \\
(0.0359)\end{array}$ \\
\hline Controls & No & Yes & No & Yes & No & Yes & No & Yes \\
\hline Municipalities & 399 & 399 & 399 & 399 & 399 & 399 & 399 & 399 \\
\hline
\end{tabular}

The table reports results of the Regression Discontinuity design described in Section 2. The running variable is the distance between the municipality's poverty rank and the provinical eligibility threshold. Local linear regressions control for flexible trends of the running variable on each side of the eligibility threshold and use triangular kernel weights with a bandwidth of 6 ranks. Quadratic regressions control for flexible quadratic trends of the running variable on both sides of the threshold. For poisson models, reported values are marginal effects. ${ }^{*},{ }^{* * * * *}$ denote statistical significance of the underlying coefficient at the $10 \%, 5 \%$ and $1 \%$ levels. Standard errors are clustered at the province level. Control variables are shown in Table 2 . All specifications include year fixed effects. 
Table 5: Robustness Tests for Continuity of Observables Across the Threshold

\begin{tabular}{lcc}
\hline \hline & \multicolumn{2}{c}{ Parameter associated with eligibility } \\
\hline & Local Linear & Quadratic \\
Dependent variable: & 4381.1 & 6837.4 \\
& $(3174.8)$ & $(5725.1)$ \\
Population & 0.074 & 11.68 \\
Percentage of villages with highway access & $(0.051)$ & $(7.899)$ \\
& 0.0635 & 0.0691 \\
Ethnic fractionalization & $(0.0489)$ & $(0.0824)$ \\
& 0.0363 & 0.0004 \\
Religious fractionalization & $(0.0401)$ & $(0.0674)$ \\
& -0.0157 & -0.0207 \\
Percent Muslim & $(0.0247)$ & $(0.0388)$ \\
& -0.0332 & -0.121 \\
Affected by insurgents in 2001 & $(0.0855)$ & $(0.146)$ \\
& & \\
HH access to electricity & 0.0096 & 0.0334 \\
& $(0.027)$ & $(0.0472)$ \\
HH access to indoor plumbing & 0.0077 & 0.0560 \\
\hline Observations & $(0.0324)$ & $(0.0542)$ \\
\hline \hline
\end{tabular}

The table reports results of the Regression Discontinuity design described in Section 2. The running variable is the distance between the municipality's poverty rank and the provinical eligibility threshold. The dependent variable is given in the row (each row reports the result of a different regression). Reported values are the coefficients associated with eligibility for KALAHICIDSS. Local linear regressions control for flexible trends of the running variable on each side of the eligibility threshold and use triangular kernel weights with a bandwidth of 6 ranks. Quadratic regressions control for flexible quadratic trends of the running variable on both sides of the threshold. ${ }^{*},{ }^{* * * *}$ denote statistical significance of the underlying coefficient at the $10 \%$, $5 \%$ and $1 \%$ levels. Standard errors are clustered at the province level. All specifications include year fixed effects. 
Table 6: Robustness to Choice of Bandwidth

\begin{tabular}{|c|c|c|c|c|c|c|}
\hline & \multicolumn{6}{|c|}{ Local linear regressions with bandwidth: } \\
\hline & 1 & 2 & 3 & 4 & 5 & 6 \\
\hline \multicolumn{7}{|c|}{ Panel A: Entire program period } \\
\hline Poisson QMLE & $\begin{array}{c}0.0841^{* * *} \\
(0.0339)\end{array}$ & $\begin{array}{c}0.886^{*} \\
(0.0531)\end{array}$ & $\begin{array}{c}0.950^{* * *} \\
(0.0378)\end{array}$ & $\begin{array}{c}0.0955^{* * *} \\
(0.0299)\end{array}$ & $\begin{array}{c}0.834^{* * *} \\
(0.0262)\end{array}$ & $\begin{array}{c}0.0712^{\text {****}} \\
(0.0235)\end{array}$ \\
\hline OLS & $\begin{array}{c}0.0752^{* *} \\
(0.0338)\end{array}$ & $\begin{array}{c}0.102^{* *} \\
(0.0553)\end{array}$ & $\begin{array}{c}0.106^{* *} \\
(0.0433)\end{array}$ & $\begin{array}{c}0.0101^{* * *} \\
(0.0363)\end{array}$ & $\begin{array}{c}0.0851^{* *} \\
(0.0313)\end{array}$ & $\begin{array}{c}0.0729^{* *} \\
(0.0280)\end{array}$ \\
\hline \multicolumn{7}{|c|}{ Panel B: Pre-program period } \\
\hline Poisson QMLE & $\begin{array}{l}-0.0177 \\
(0.0405)\end{array}$ & $\begin{array}{c}-0.0453 \\
(0.0670)\end{array}$ & $\begin{array}{c}-0.0221 \\
(0.0478)\end{array}$ & $\begin{array}{c}-0.0071 \\
(0.0429)\end{array}$ & $\begin{array}{c}-0.0034 \\
(0.0388)\end{array}$ & $\begin{array}{l}-0.0050 \\
(0.0340)\end{array}$ \\
\hline OLS & $\begin{array}{c}-0.0245 \\
(0.0479)\end{array}$ & $\begin{array}{c}-0.0527 \\
(0.0803)\end{array}$ & $\begin{array}{c}-0.0243 \\
(0.0614)\end{array}$ & $\begin{array}{c}-0.0078 \\
(0.0533)\end{array}$ & $\begin{array}{c}-0.0030 \\
(0.0466)\end{array}$ & $\begin{array}{c}-0.0031 \\
(0.0398)\end{array}$ \\
\hline \multicolumn{7}{|c|}{ Panel C: Social preparation phase } \\
\hline Poisson QMLE & $\begin{array}{c}0.414^{* *} \\
(0.215)\end{array}$ & $\begin{array}{c}0.498^{* *} \\
(0.271)\end{array}$ & $\begin{array}{c}0.377^{* *} \\
(0.195)\end{array}$ & $\begin{array}{c}0.327^{* * *} \\
(0.142)\end{array}$ & $\begin{array}{c}0.296^{* * *} \\
(0.117)\end{array}$ & $\begin{array}{c}0.270^{* * *} \\
(0.102)\end{array}$ \\
\hline OLS & $\begin{array}{c}0.339^{* *} \\
(0.156)\end{array}$ & $\begin{array}{c}0.498^{* *} \\
(0.242)\end{array}$ & $\begin{array}{c}0.433^{* *} \\
(0.206)\end{array}$ & $\begin{array}{c}0.381^{* *} \\
(0.172)\end{array}$ & $\begin{array}{c}0.334^{* *} \\
(0.146)\end{array}$ & $\begin{array}{c}0.304^{* *} \\
(0.131)\end{array}$ \\
\hline \multicolumn{7}{|c|}{ Panel D: Rest of program period } \\
\hline Poisson QMLE & $\begin{array}{c}0.0218 \\
(0.0302)\end{array}$ & $\begin{array}{c}0.0133 \\
(0.0468)\end{array}$ & $\begin{array}{c}0.0377 \\
(0.0332)\end{array}$ & $\begin{array}{c}0.0463 \\
(0.0292)\end{array}$ & $\begin{array}{c}0.0379 \\
(0.0275)\end{array}$ & $\begin{array}{c}0.0285 \\
(0.0260)\end{array}$ \\
\hline OLS & 0.0224 & $\begin{array}{c}0.0227 \\
(0.0303)\end{array}$ & $\begin{array}{c}0.0411 \\
(0.0359)\end{array}$ & $\begin{array}{c}0.0453 \\
(0.0320)\end{array}$ & $\begin{array}{c}0.0353 \\
(0.0295)\end{array}$ & $\begin{array}{c}0.0268 \\
(0.0277)\end{array}$ \\
\hline Controls & Yes & Yes & Yes & Yes & Yes & Yes \\
\hline Municipalities & 82 & 160 & 232 & 293 & 349 & 399 \\
\hline
\end{tabular}

The table reports results of the Regression Discontinuity design described in Section 2. The running variable is the distance between the municipality's poverty rank and the provinical eligibility threshold. All reported results are estimates of the effect of eligibility from local linear regressions that use triangular kernel weights with bandwidths between 2 and 6 . All models control for flexible trends of the running variable on each side of the eligibility threshold. For poisson models, reported values are marginal effects. ${ }^{*},{ }^{* * * * *}$ denote statistical significance of the underlying coefficient at the $10 \%, 5 \%$ and $1 \%$ levels. Standard errors are clustered at the province level. All specifications include the control variables shown in Table 2 and year fixed effects. 
Table 7: Who Suffers the Casualties?

\begin{tabular}{|c|c|c|c|c|}
\hline & \multicolumn{2}{|c|}{ Local Linear } & \multicolumn{2}{|c|}{ Quadratic } \\
\hline & $\begin{array}{l}\text { Poisson } \\
\text { (1) }\end{array}$ & $\begin{array}{l}\text { OLS } \\
(2)\end{array}$ & $\begin{array}{l}\text { Poisson } \\
\text { (3) }\end{array}$ & $\begin{array}{l}\text { OLS } \\
(4)\end{array}$ \\
\hline \multicolumn{5}{|c|}{ Dependent variable: Casualties in insurgent-initiated incidents } \\
\hline Eligible & $\begin{array}{c}0.0570^{* * *} \\
(0.0165)\end{array}$ & $\begin{array}{c}0.0588^{* * *} \\
(0.0200)\end{array}$ & $\begin{array}{c}0.0693^{* * *} \\
(0.0210)\end{array}$ & $\begin{array}{c}0.0753^{* *} \\
(0.0285)\end{array}$ \\
\hline \multicolumn{5}{|c|}{ Dependent variable: Casualties in government-initiated incidents } \\
\hline Eligible & $\begin{array}{c}0.0131 \\
(0.0171)\end{array}$ & $\begin{array}{c}0.0128 \\
(0.0183)\end{array}$ & $\begin{array}{c}0.0291 \\
(0.0211)\end{array}$ & $\begin{array}{c}0.326 \\
(0.0263)\end{array}$ \\
\hline \multicolumn{5}{|c|}{ Dependent variable: Casualties suffered by government forces } \\
\hline Eligible & $\begin{array}{c}0.0536^{* * *} \\
(0.0187)\end{array}$ & $\begin{array}{c}0.0551^{* *} \\
(0.0215)\end{array}$ & $\begin{array}{c}0.0728^{* * *} \\
(0.0221)\end{array}$ & $\begin{array}{c}0.0885 * * * \\
(0.0299)\end{array}$ \\
\hline \multicolumn{5}{|c|}{ Dependent variable: Casualties suffered by insurgents } \\
\hline Eligible & $\begin{array}{c}0.0098 \\
(0.0097)\end{array}$ & $\begin{array}{c}0.0109 \\
(0.0113)\end{array}$ & $\begin{array}{c}0.0109 \\
(0.0109)\end{array}$ & $\begin{array}{c}0.0127 \\
(0.0160)\end{array}$ \\
\hline \multicolumn{5}{|c|}{ Dependent variable: Casualties suffered by civilians } \\
\hline Eligible & $\begin{array}{c}0.0166^{* * *} \\
(0.0055)\end{array}$ & $\begin{array}{c}0.0129^{* *} \\
(0.0059)\end{array}$ & $\begin{array}{c}.0268^{* * *} \\
(0.0107)\end{array}$ & $\begin{array}{l}0.0152^{*} \\
(0.0084)\end{array}$ \\
\hline Controls & Yes & Yes & Yes & Yes \\
\hline Obs & 14364 & 14364 & 14364 & 14364 \\
\hline Municipalities & 399 & 399 & 399 & 399 \\
\hline
\end{tabular}

The table reports results of the Regression Discontinuity design described in Section 2. The running variable is the distance between the municipality's poverty rank and the provinical eligibility threshold. Local linear regressions use triangular kernel weights with a bandwidth of 6 ranks. For poisson models, reported values are marginal effects. Local linear regressions control for flexible trends of the running variable on each side of the eligibility threshold and use triangular kernel weights with a bandwidth of 6 ranks. Quadratic regressions control for flexible quadratic trends of the running variable on both sides of the threshold. *, ***** denote statistical significance of the underlying coefficient at the $10 \%, 5 \%$ and $1 \%$ levels. Standard errors are clustered at the province level. All specifications include the control variables shown in Table 2 and year fixed effects. 
Table 8: Which Conflicts are Affected?

\begin{tabular}{|c|c|c|c|c|}
\hline & \multicolumn{2}{|c|}{ Local Linear } & \multicolumn{2}{|c|}{ Quadratic } \\
\hline & $\begin{array}{l}\text { Poisson } \\
\text { (1) }\end{array}$ & $\begin{array}{c}\text { OLS } \\
(2)\end{array}$ & $\begin{array}{c}\text { Poisson } \\
(3)\end{array}$ & $\begin{array}{c}\text { OLS } \\
(4)\end{array}$ \\
\hline \multicolumn{5}{|c|}{ Dep. var.: Casualties suffered in incidents involving the NPA } \\
\hline Eligible & $\begin{array}{c}0.0577^{* * *} \\
(0.0216)\end{array}$ & $\begin{array}{c}0.0613^{* *} \\
(0.0251)\end{array}$ & $\begin{array}{c}0.0692^{* * *} \\
(0.0252)\end{array}$ & $\begin{array}{c}0.0880^{* *} \\
(0.0353)\end{array}$ \\
\hline \multicolumn{5}{|c|}{ Dep. var.: Casualties suffered in incidents involving the MILF } \\
\hline Eligible & $\begin{array}{c}0.0267^{* * *} \\
(0.0105)\end{array}$ & $\begin{array}{c}0.0223 \\
(0.0148)\end{array}$ & $\begin{array}{c}0.0340^{* * *} \\
(0.0082)\end{array}$ & $\begin{array}{c}0.0295 \\
(0.0192)\end{array}$ \\
\hline \multicolumn{5}{|c|}{ Dep. var.: Casualties suffered in incidents involving Lawless Elements } \\
\hline Eligible & $\begin{array}{c}-0.0119^{* *} \\
(0.0112)\end{array}$ & $\begin{array}{l}-0.0122 \\
(0.0074)\end{array}$ & $\begin{array}{l}-0.0094 \\
(0.0080)\end{array}$ & $\begin{array}{l}-0.0123 \\
(0.0112)\end{array}$ \\
\hline Controls & Yes & Yes & Yes & Yes \\
\hline Observations & 14364 & 14364 & 14364 & 14364 \\
\hline Municipalities & 399 & 399 & 399 & 399 \\
\hline
\end{tabular}

The table reports results of the Regression Discontinuity design described in Section 2. The running variable is the distance between the municipality's poverty rank and the provinical eligibility threshold. Local linear regressions control for flexible trends of the running variable on each side of the eligibility threshold and use triangular kernel weights with a bandwidth of 6 ranks. Quadratic regressions control for flexible quadratic trends of the running variable on both sides of the threshold. For poisson models, reported values are marginal effects. ${ }^{*},{ }^{* *} * *$ denote statistical significance of the underlying coefficient at the $10 \%, 5 \%$ and $1 \%$ levels. Standard errors are clustered at the province level. All specifications include the control variables shown in Table 2 and year fixed effects. 
Table 9: Spillovers to Nearby Municipalities

\begin{tabular}{lccccc}
\hline \hline & \multicolumn{5}{c}{ Dependent variable: Mean casualties within: } \\
& $10 \mathrm{~km}$ & $20 \mathrm{~km}$ & $30 \mathrm{~km}$ & $40 \mathrm{~km}$ & $50 \mathrm{~km}$ \\
\hline \hline Panel A: Entire Program Period & & & & & \\
\hline Eligible & -0.0280 & -0.0317 & -0.0274 & -0.0214 & -0.0103 \\
& $(0.0222)$ & $(0.0256)$ & $(0.0227)$ & $(0.0153)$ & $(0.0085)$ \\
& & & & & \\
\hline Panel B: Pre-Program Period & & & & & \\
\hline Eligible & -0.0245 & -0.0378 & -0.0336 & -0.0217 & -0.0104 \\
& $(0.0174)$ & $(0.0271)$ & $(0.0207)$ & $(0.0136)$ & $(0.0090)$ \\
& & & & & \\
\hline \hline Mean \# of muni. within distance: & 3.65 & 13.06 & 25.16 & 35.03 & 40.93 \\
& {$[2.61]$} & {$[7.85]$} & {$[12.62]$} & {$[11.87]$} & {$[8.35]$} \\
\hline Controls & Yes & Yes & Yes & Yes & Yes \\
\hline Municipalities & 399 & 399 & 399 & 399 & 399 \\
\hline \hline
\end{tabular}

The table reports results of the Regression Discontinuity design described in Section 2. The running variable is the distance between the municipality's poverty rank and the provinical eligibility threshold. All results are OLS estimates of the effect of eligibility on mean casualties in municipalities within distances between 10 and $40 \mathrm{~km}$ (not including the observed municipality itself). All estimates are from local linear models that control for flexible trends of the running variable on each side of the eligibility threshold and use a triangular kernel with a bandwidth of 6 . All specifications include year fixed effects and the control variables in Table 2. ${ }^{*},{ }^{* * * * *}$ denote statistical significance of the underlying coefficient at the $10 \%, 5 \%$ and $1 \%$ levels. Standard errors, clustered at the province level, are reported in parentheses. Standard deviations of mean number of municipalities are reported in square brackets. All specifications include the control variables shown in Table 2 and year fixed effects. 


\section{Figure 1: Map of KALAHI-CIDSS Municipalities}

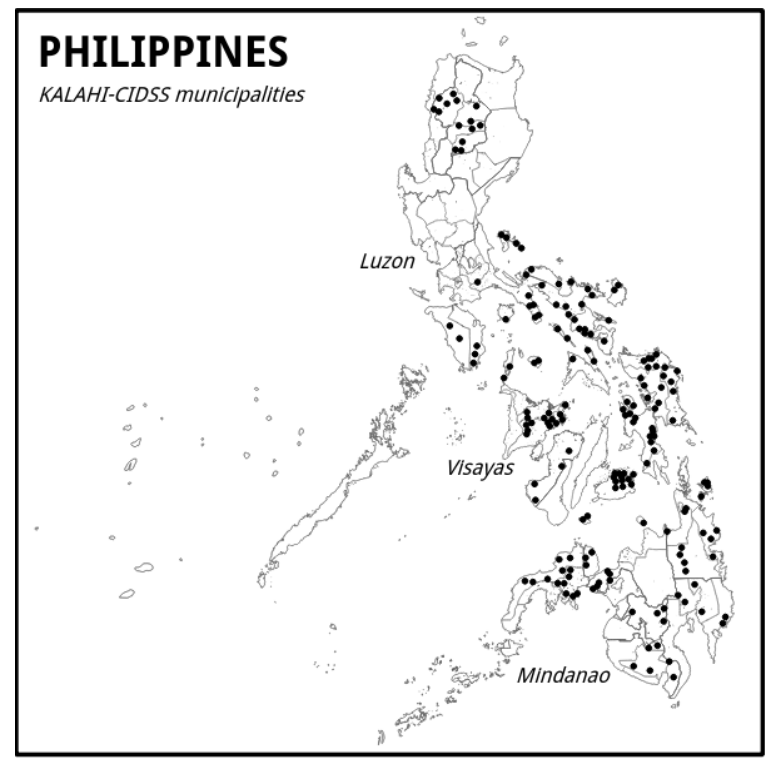

Black dots indicate municipalities that participated in KALAHI-CIDSS in the period 2003-2009.

Figure 2: The Effect of Eligibility on Participation

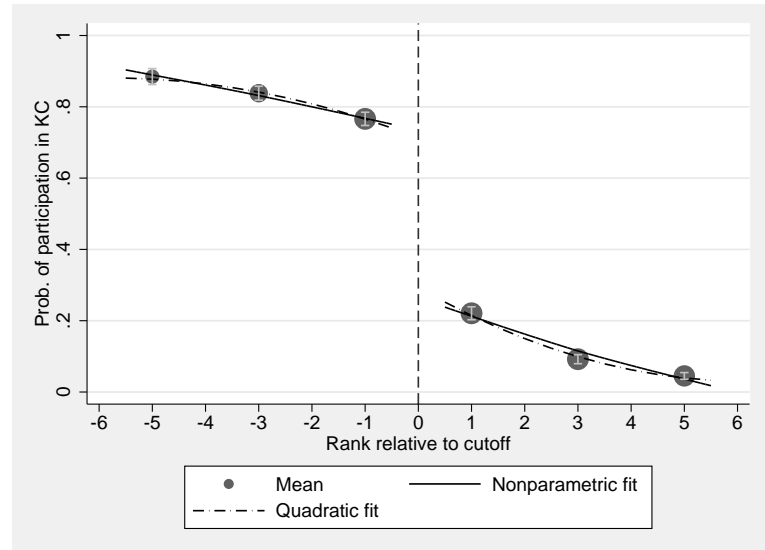

The figure presents the relationship between the probability of participating in the KALAHI-CIDSS program and the running variable of the RD design, which is the distance between the municipality's poverty rank and the provincial eligibility threshold. Scatter dots represent mean outcomes of bins with a width of 2 poverty ranks. The vertical bars are $95 \%$ confidence intervals. Dashed lines are quadratic fits, separately estimated on both sides of the eligibility threshold. Solid lines are nonparametric fits from a local linear regression that uses triangular kernels with a bandwidth of 6 , separately estimated on both sides of the eligibility threshold. 
Figure 3: The Effect of Eligibility on Casualties
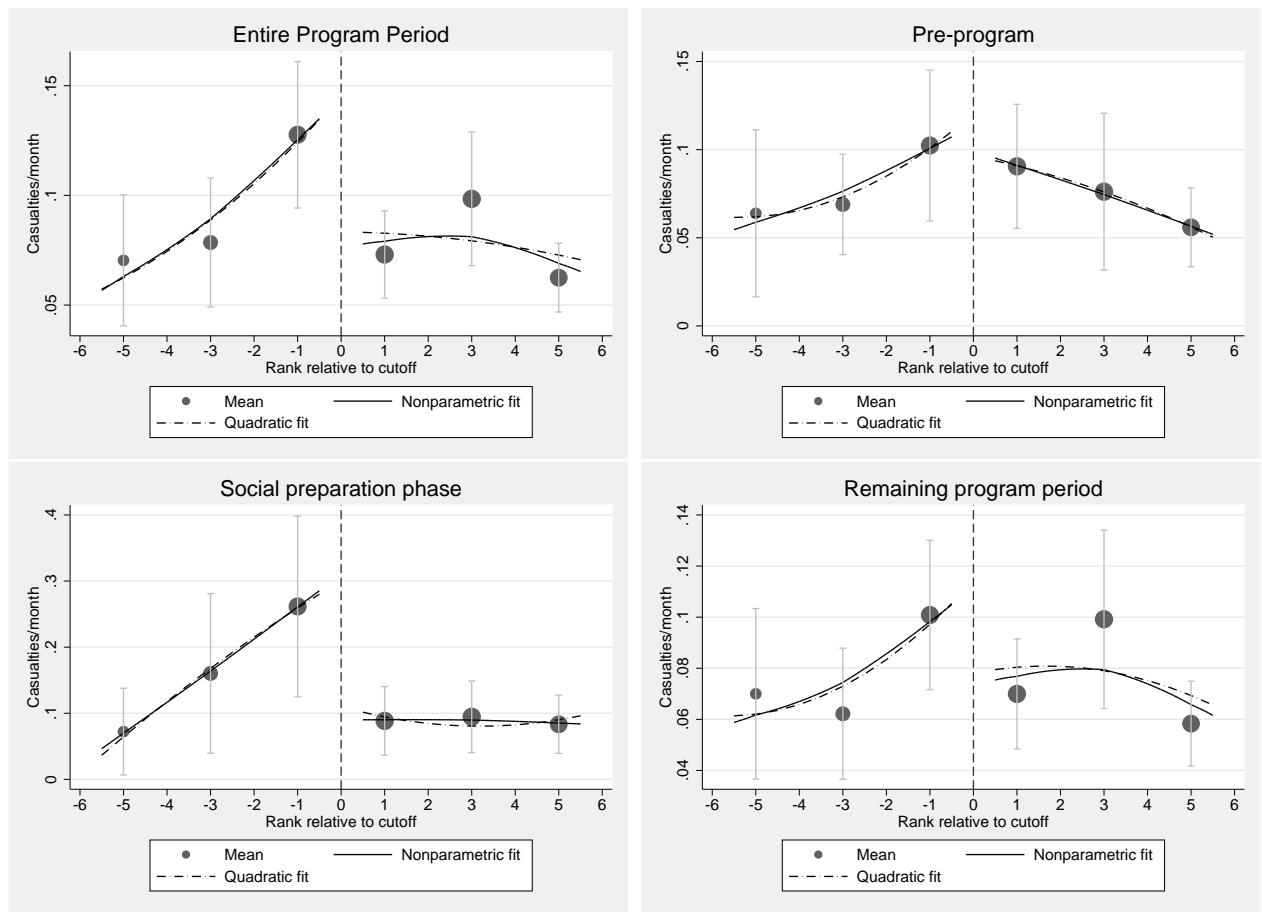

The figure presents the relationship between the number of casualties experienced during the program period and the running variable of the RD design, which is the distance between the municipality's poverty rank and the provincial eligibility threshold. Scatter dots represent mean outcomes of bins with a width of 2 poverty ranks. The vertical bars are $95 \%$ confidence intervals. Dashed lines are quadratic fits, separately estimated on both sides of the eligibility threshold. Solid lines are nonparametric fits from a local linear regression that uses triangular kernels with a bandwidth of 6 , separately estimated on both sides of the eligibility threshold. 
Figure 4: Robustness Tests for Continuity of Observables Across the Threshold
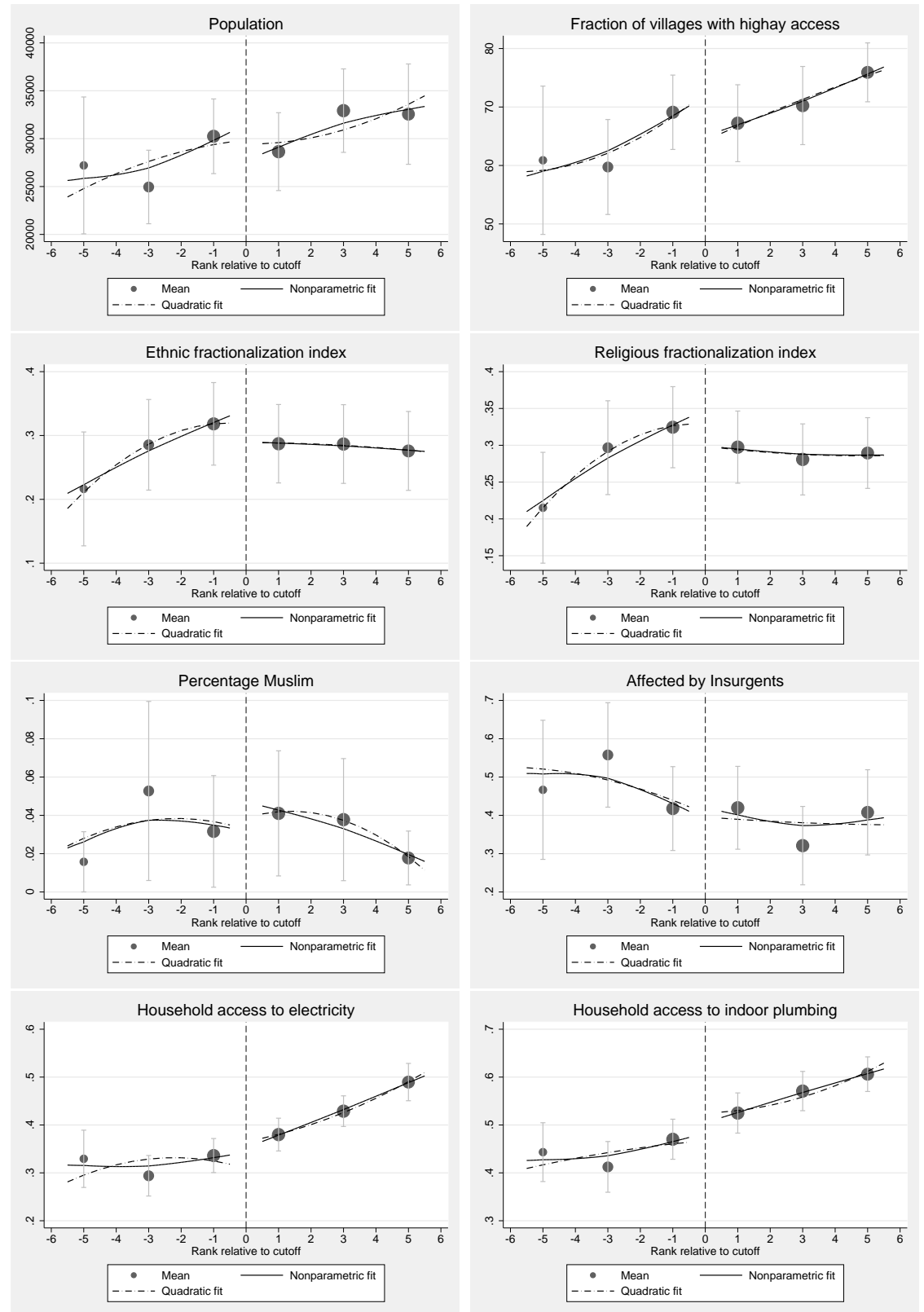

The figure presents the relationship between the running variable of the RD design, which is the distance between the municipality's poverty rank and the provinical eligibility threshold, and a number of control variables. Scatter dots represent means of bins with a bandwidth of 1 . Dashed lines are quadratic fits, separately estimated on both sides of the eligibility threshold. Solid lines are nonparametric fits from a local linear regression that uses triangular kernels with a bandwidth of 6 , separately estimated on both sides of the eligibility threshold. 
Figure 5: Who Initiates the Violence and Who Suffers the Casualties?
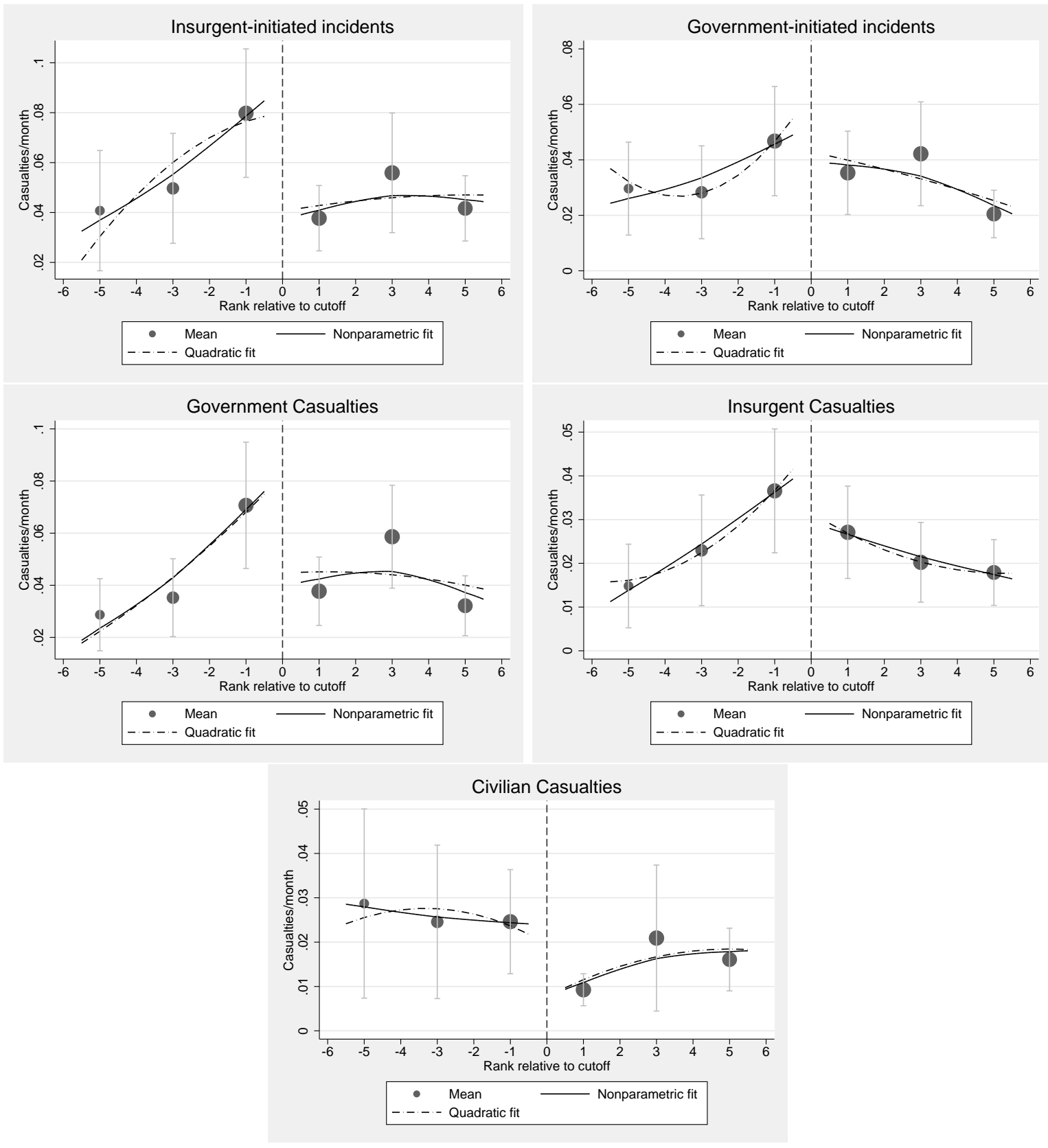

The figure presents the relationship between the number of casualties experienced by different groups during the program period and the running variable of the RD design, which is the distance between the municipality's poverty rank and the provincial eligibility threshold. Scatter dots represent mean outcomes of bins with a width of 2 poverty ranks. The vertical bars are $95 \%$ confidence intervals. Dashed lines are quadratic fits, separately estimated on both sides of the eligibility threshold. Solid lines are nonparametric fits from a local linear regression that uses triangular kernels with a bandwidth of 6 , separately estimated on both sides of the eligibility threshold. 


\section{Figure 6: The Program's Effect on Different Armed Groups}
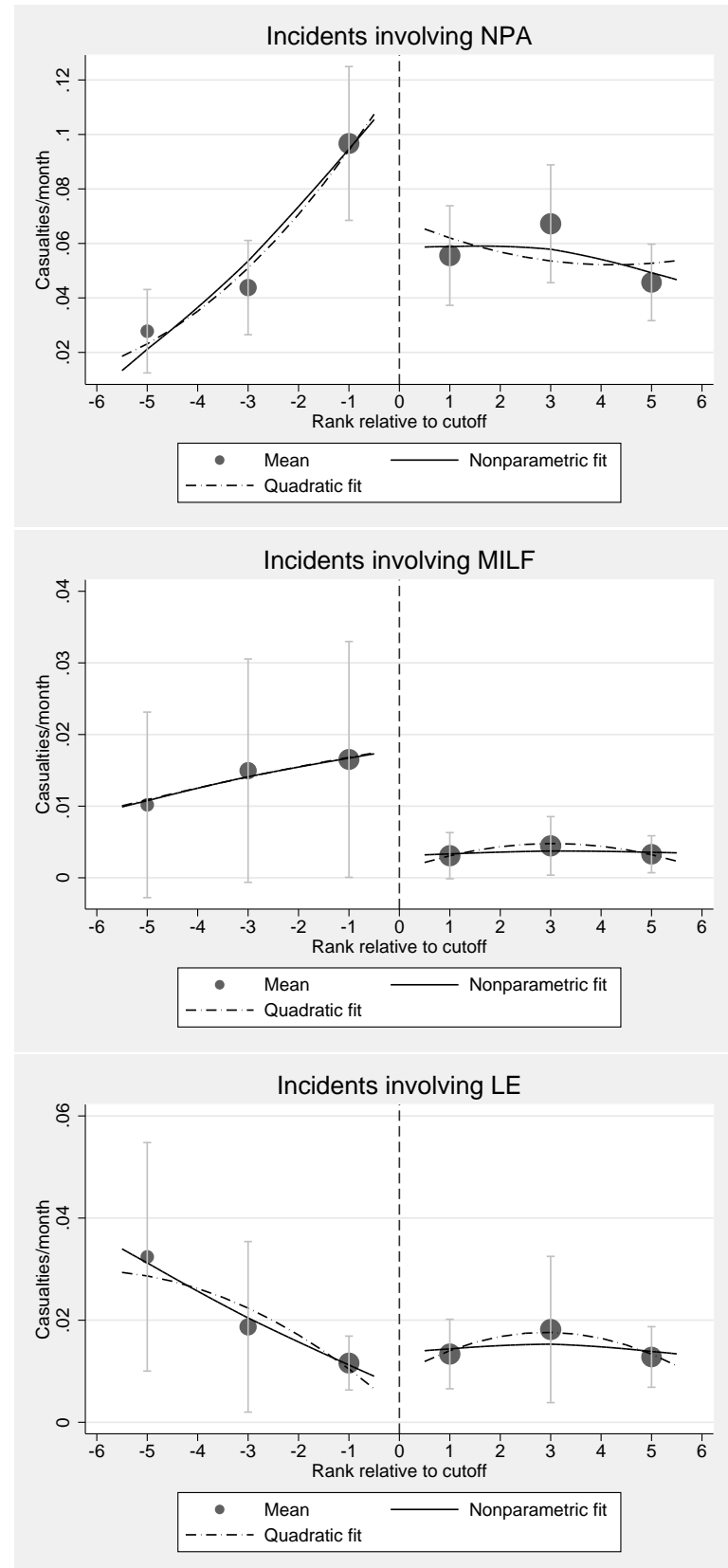

The figure presents the relationship between the number of casualties experienced in incidients involving different armed groups during the program period and the running variable of the RD design, which is the distance between the municipality's poverty rank and the provincial eligibility threshold. Scatter dots represent mean outcomes of bins with a width of 2 poverty ranks. The vertical bars are 95\% confidence intervals. Dashed lines are quadratic fits, separately estimated on both sides of the eligibility threshold. Solid lines are nonparametric fits from a local linear regression that uses triangular kernels with a bandwidth of 6 , separately estimated on both sides of the eligibility threshold. 
Figure 7: Spillover Effects

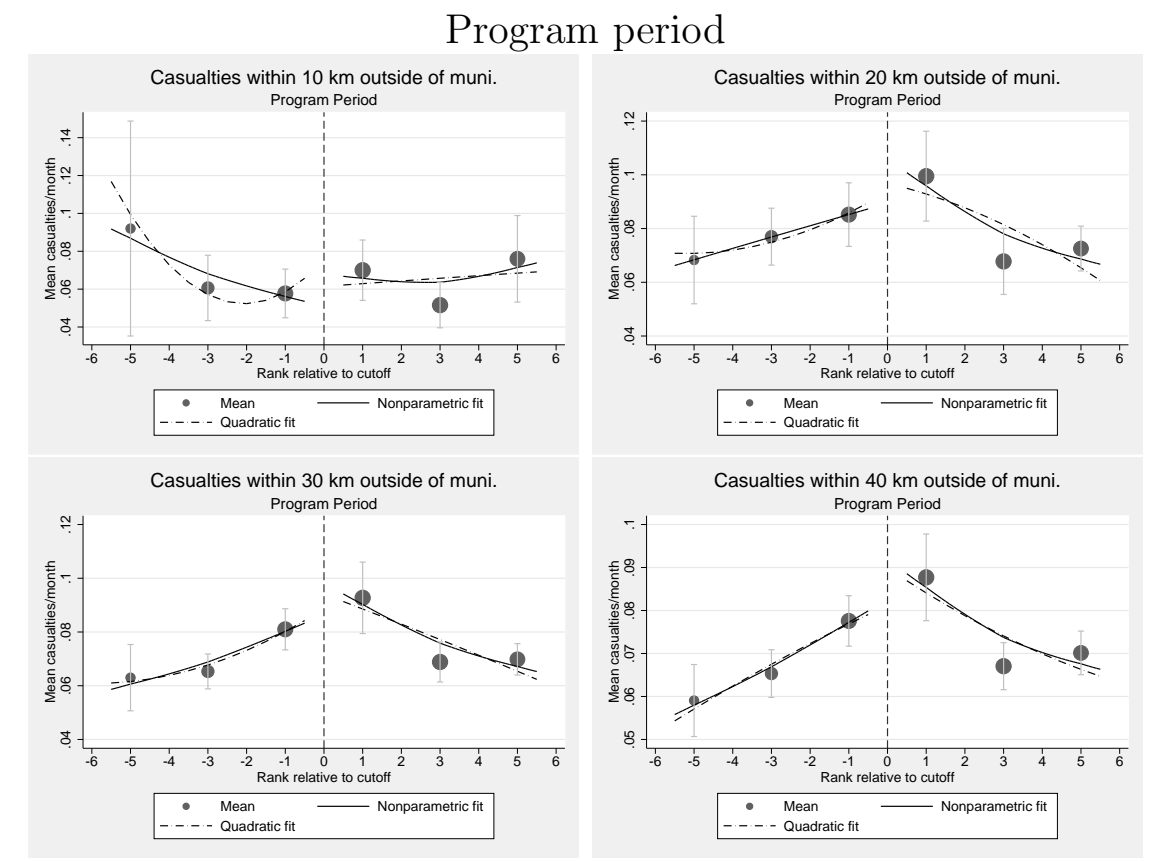

Pre-program period

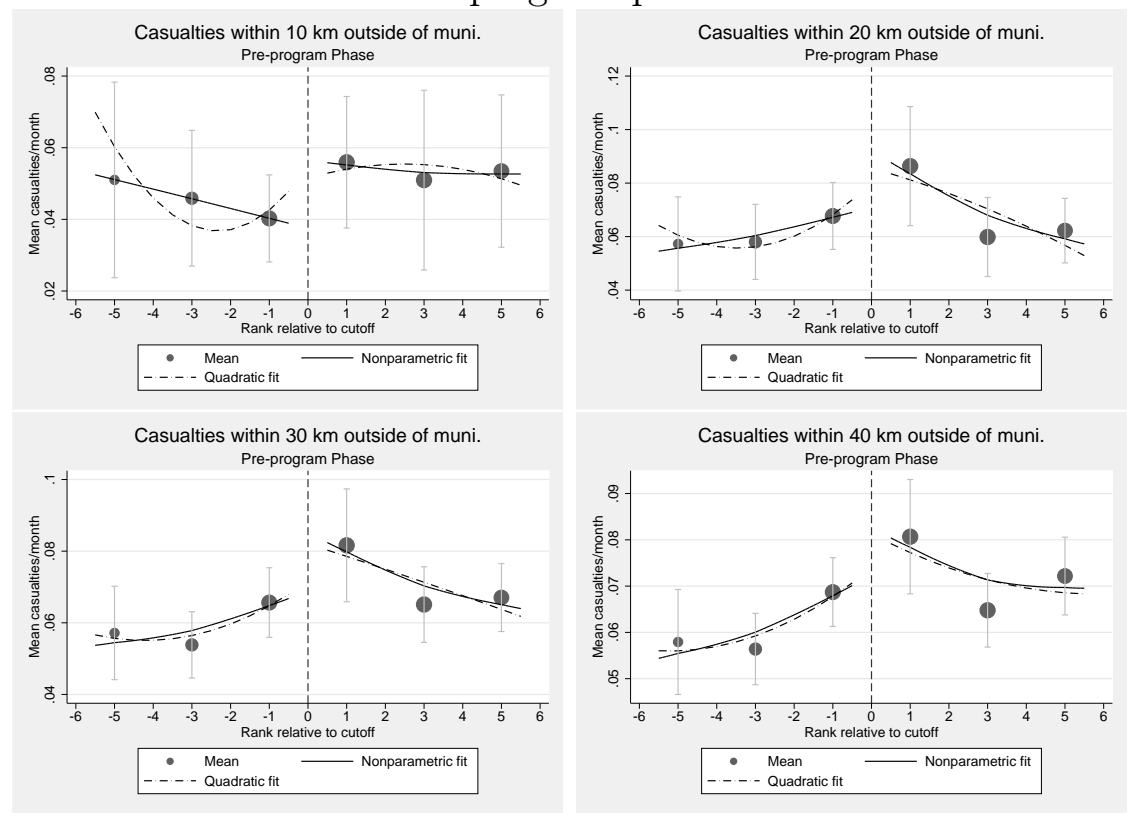

The figure presents the relationship between the running variable of the RD design, which is the distance between the municipality's poverty rank and the provinical eligibility threshold, and a number of control variables. Scatter dots represent means of bins with a bandwidth of 1 . Dashed lines are quadratic fits, separately estimated on both sides of the eligibility threshold. Solid lines are nonparametric fits from a local linear regression that uses triangular kernels with a bandwidth of 6 , separately estimated on both sides of the eligibility threshold. 


\section{Appendix - for online publication}

This appendix presents the results of a number of robustnes tests of our empirical approach.

\subsection{Robustness Tests for Endogenous Timing}

\subsubsection{Results for Batch A Provinces Only}

We first test for a possible effect of endogenous timing by reporting results for the subsample of Batch A provinces only. As mentioned in Section 2 endogenous timing is not an issue for municipalities in Batch A provinces, since all of them had the same start date for the program and since this date was set before municipal eligibility was determined. Table 10 reports estimates of the effect of the KALAHI-CIDSS program on conflict in this subsample. The results are similar to the ones for the entire sample reported in Table 4. The top panel shows that the program had a positive and statistically significant effect on casualties in the entire program period. The lower three panels show that this effect is due to a large and statistically significant increase in casualties in the social preparation phase. There is no statistically significant effect in the pre-program period and the later program period, after the social preparation phase. The point estimates are similar to those for the whole sample, though they are somewhat larger in the social preparation phase, which suggests that the implementing agency may have timed the program in Batch B provinces to avoid conflict in the social preparation phase.

\subsubsection{Alternative Specification of the Start Date in Batch B Provinces}

We now test for sensitivity to the use of August 2006 as the program's start date in Batch B provinces. For this test, we weight all observations in Batch B according to the exante probability with which municipalities were covered by the program at the time of the 
observation. Out of the 117 municipalities that were covered in Batch B, 34 were covered in Phase 3A, 29 in Phase 3B and the remaining 54 in Phase 4. We therefore assigned a weight of $\frac{34}{117}$ to municipalities during the program period of Phase $3 \mathrm{~A}$, which started in October 2004, a weight of $\frac{29}{117}$ to observations during the period of Phase, which started in January 2006, and a weight of $\frac{54}{117}$ to observations in the program period of Phase 4 , which started in August 2006. Observations outside of the program period of any phase receive a weight of zero. For observations that fall into the program period of several phases the weights were assigned additively. For example, observations in March 2006, when Phases 3A and 3B were both active, receive a weight of $\frac{34+29}{117}$. As usual, we define the program period as ranging from the start of the social preparation phase, 6 months before the program's official start date, until the end of the third program cycle, 36 months after the official start date. As before, observations in Batch A provinces are included with a weight of 1 if they are in the program period of Batch $\mathrm{A}$ and given a weight of 0 otherwise.

Table 11 shows that the results of this analysis is not substantially different from the results of Table 4. The estimates that use probability weighting are slightly smaller, but similar in magnitude and similarly statistically significant. There is therefore no evidence that our results are driven by the choice of August 2006 as the program's start date in Batch B provinces.

\subsection{Smoothness at "Pseudo-Thresholds"}

We now test whether there are discontinuities in conflict casualties at other places away from the threshold. Finding discontinuities at those "pseudo-thresholds", where eligibility does not change, would raise the concern that our results are due to mis-specified non-linearities in the relationship between the running variable and the outcome Imbens and Lemieux (2008). Following Imbens and Lemieux's recommendation we look for discontinuities at two pseudothresholds: the medians of the running variable for eligible and ineligible municipalities, 
located at -2 and 3 relative poverty ranks, respectively. Table 13 shows that we find no statistically significant evidence of discontinuities at these two thresholds.

\subsection{Smoothness of Variables that Should not Have Been Affected by KALAHI-CIDSS}

As an additional robustness test, we test whether barely eligible and barely ineligible municipalites differed in outcomes during the program period that should not have been affected by the program. Doing so is difficult in this context, since it is not easy to find data on such outcomes in the Philippines. The most reliable municipality level data on relevant outcomes comes from the Philippines National Census, which was only conducted in 2000, before the program started, and in 2010, after the program had concluded. Given the data limitations, we only test the program's effect on household poverty incidence in the year 2003, which was estimated by a World Bank study using a proxy means test. In 2003, the program was active in Batch A provinces. Since the actual program implementation only began in mid-2003, the program should not have affected household poverty yet. Finding an effect would therefore indicate systematic differences in time-varying unobserved variables across the eligibility threshold.

The results in Table 12 show no evidence of this. The program's estimated effect on municipal poverty incidence and poverty gap in 2003 are small and statistically insignificant. This result is unchanged if we look only at Batch A provinces, in which the program was already active in 2003 . 
Table 10: Results for Batch A provinces only

\begin{tabular}{|c|c|c|c|c|c|c|c|c|}
\hline & \multicolumn{4}{|c|}{ Poisson QMLE } & \multicolumn{4}{|c|}{ OLS } \\
\hline & \multicolumn{2}{|c|}{ Local Linear } & \multicolumn{2}{|c|}{ Quadratic } & \multicolumn{2}{|c|}{ Local Linear } & \multicolumn{2}{|c|}{ Quadratic } \\
\hline & $(1)$ & $(2)$ & $(3)$ & $(4)$ & $(5)$ & $(6)$ & $(7)$ & $(8)$ \\
\hline \multicolumn{9}{|c|}{ Panel A: Entire program period (7812 municipality-month observations) } \\
\hline \multirow[t]{2}{*}{ Eligible } & $0.0908^{* *}$ & $0.0744^{* *}$ & $0.0966^{* *}$ & $0.908^{* * *}$ & $0.108^{* *}$ & $0.0920^{* *}$ & $0.146^{* *}$ & $0.127^{*}$ \\
\hline & $(0.0403)$ & $(0.0327)$ & $(0.0483)$ & $(0.0412)$ & $(0.0468)$ & $(0.0437)$ & $(0.0697)$ & $(0.0648)$ \\
\hline \multicolumn{9}{|c|}{ Panel B: Pre-program period (2604 municipality-month observations) } \\
\hline \multirow[t]{2}{*}{ Eligible } & -0.0381 & -0.0267 & -0.0462 & -0.0281 & -0.0383 & -0.0387 & -0.0608 & -0.0547 \\
\hline & $(0.0580)$ & $(0.0514)$ & $(0.0717)$ & $(0.0639)$ & $(0.0635)$ & $(0.0647)$ & $(0.0967)$ & $(0.0991)$ \\
\hline \multicolumn{9}{|c|}{ Panel C: Social preparation phase (1302 municipality-month observations) } \\
\hline \multirow[t]{2}{*}{ Eligible } & $0.493^{* * *}$ & $0.534^{* * *}$ & $0.396 * * *$ & $0.450^{* * *}$ & $0.546^{* *}$ & $0.568^{* *}$ & $0.682^{* *}$ & $0.690^{* *}$ \\
\hline & $(0.233)$ & $(0.176)$ & $(0.216)$ & $(0166)$ & $(0.227)$ & $(0.216)$ & $(0.318)$ & $(0.297)$ \\
\hline \multicolumn{9}{|c|}{ Panel D: Rest of program period (6510 municipality-month observations) } \\
\hline \multirow[t]{2}{*}{ Eligible } & 0.0184 & -0.0102 & 0.0309 & 0.0101 & 0.0203 & -0.0033 & 0.0384 & 0.0141 \\
\hline & $(0.0343)$ & $(0.0285)$ & $(0.0399)$ & $(0.0308)$ & $(0.0377)$ & $(0.0362)$ & $(0.0524)$ & $(0.0488)$ \\
\hline Controls & $\mathrm{No}$ & $\overline{\text { Yes }}$ & $\mathrm{No}$ & Yes & $\mathrm{No}$ & Yes & No & Yes \\
\hline Municipalities & 217 & 217 & 217 & 217 & 217 & 217 & 217 & 217 \\
\hline
\end{tabular}

The table reports results of the Regression Discontinuity design described in Section 2. All regressions are based on the subsample of Batch A provinces. The running variable (normalized poverty rank) is the distance of the municipality's poverty rank from the provinical eligibility threshold. Local linear regressions control for flexible trends of the running variable on each side of the eligibility threshold and use triangular kernel weights with a bandwidth of 6 ranks. Quadratic regressions control for flexible quadratic trends of the running variable on both sides of the threshold. For poisson models, reported values are marginal effects. ${ }^{*},{ }^{* * * *}$ denote statistical significance of the underlying coefficient at the $10 \%, 5 \%$ and $1 \%$ levels. Standard errors are clustered at the province level. All specifications include year fixed effects. 
Table 11: Alternative Specification of Start Dates for Batch B Provinces

\begin{tabular}{|c|c|c|c|c|c|c|c|c|}
\hline & \multicolumn{4}{|c|}{ Poisson QMLE } & \multicolumn{4}{|c|}{$\overline{\mathrm{OLS}}$} \\
\hline & \multicolumn{2}{|c|}{ Local Linear } & \multicolumn{2}{|c|}{ Quadratic } & \multicolumn{2}{|c|}{ Local Linear } & \multicolumn{2}{|c|}{ Quadratic } \\
\hline & $(1)$ & $(2)$ & $(3)$ & $(4)$ & $(5)$ & $(6)$ & $(7)$ & $(8)$ \\
\hline \multicolumn{9}{|c|}{ Panel A: Entire program period (14364 municipality-month observations) } \\
\hline Eligible & $\begin{array}{c}0.0693^{* * *} \\
(0.0253)\end{array}$ & $\begin{array}{c}0.0673^{* * *} \\
(0.0213)\end{array}$ & $\begin{array}{c}0.0892^{* * *} \\
(0.0340)\end{array}$ & $\begin{array}{c}0.950^{* * *} \\
(0.0280)\end{array}$ & $\begin{array}{c}0.0748^{* *} \\
(0.0281)\end{array}$ & $\begin{array}{c}0.0685^{* *} \\
(0.0258)\end{array}$ & $\begin{array}{l}0.109^{* *} \\
(0.0422)\end{array}$ & $\begin{array}{c}0.103^{* * *} \\
(0.0379)\end{array}$ \\
\hline \multicolumn{9}{|c|}{ Panel B: Pre-program period (4788 municipality-month observations) } \\
\hline Eligible & $\begin{array}{l}-0.0094 \\
(0.0351)\end{array}$ & $\begin{array}{l}-0.0130 \\
(0.0313)\end{array}$ & $\begin{array}{l}-0.0122 \\
(0.0480)\end{array}$ & $\begin{array}{l}-0.0055 \\
(0.0428)\end{array}$ & $\begin{array}{l}-0.0097 \\
(0.0372)\end{array}$ & $\begin{array}{l}-0.0149 \\
(0.0355)\end{array}$ & $\begin{array}{l}-0.0148 \\
(0.0570)\end{array}$ & $\begin{array}{c}-0.0098 \\
(0.0563)\end{array}$ \\
\hline \multicolumn{9}{|c|}{ Panel C: Social preparation phase (2394 municipality-month observations) } \\
\hline Eligible & $\begin{array}{c}0.247^{* * *} \\
(0.114)\end{array}$ & $\begin{array}{c}0.262^{* * *} \\
(0.0938)\end{array}$ & $\begin{array}{c}0.223^{* *} \\
(0.114)\end{array}$ & $\begin{array}{c}0.248^{* * *} \\
(0.103)\end{array}$ & $\begin{array}{c}0.291^{* *} \\
(0.131)\end{array}$ & $\begin{array}{c}0.307^{* *} \\
(0.128)\end{array}$ & $\begin{array}{l}0.369^{*} \\
(0.183)\end{array}$ & $\begin{array}{c}0.388^{* *} \\
(0.173)\end{array}$ \\
\hline \multicolumn{9}{|c|}{ Panel D: Rest of program period (11970 municipality-month observations) } \\
\hline Eligible & $\begin{array}{c}0.0337 \\
(0.0229)\end{array}$ & $\begin{array}{c}0.0264 \\
(0.0218)\end{array}$ & $\begin{array}{l}0.0556^{*} \\
(0.0305)\end{array}$ & $\begin{array}{c}0.0558^{* *} \\
(0.0252)\end{array}$ & $\begin{array}{c}0.0345 \\
(0.0239)\end{array}$ & $\begin{array}{c}0.0235 \\
(0.0232)\end{array}$ & $\begin{array}{l}0.0607^{*} \\
(0.0341)\end{array}$ & $\begin{array}{c}0.0497 \\
(0.0310)\end{array}$ \\
\hline Controls & No & Yes & No & Yes & No & Yes & $\mathrm{No}$ & Yes \\
\hline Municipalities & 399 & 399 & 399 & 399 & 399 & 399 & 399 & 399 \\
\hline
\end{tabular}

The table reports results of the Regression Discontinuity design described in Section 2. All regressions use the weighting scheme for the program's start date described in Section 7.1.2. The running variable is the distance between the municipality's poverty rank and the provinical eligibility threshold. Local linear regressions control for flexible trends of the running variable on each side of the eligibility threshold and use triangular kernel weights with a bandwidth of 6 ranks. Quadratic regressions control for flexible quadratic trends of the running variable on both sides of the threshold. For poisson models, reported values are marginal effects. ${ }^{*}, * * * *$ denote statistical significance of the underlying coefficient at the $10 \%, 5 \%$ and $1 \%$ levels. Standard errors are clustered at the province level. Control variables are shown in Table 2. All specifications include year fixed effects. 
Table 12: Placebo Test for Effect on 2003 Household Poverty

\begin{tabular}{|c|c|c|c|c|}
\hline & \multicolumn{2}{|c|}{ Dep. var: 2003 poverty incidence (\%) } & \multicolumn{2}{|c|}{ Dep. var: 2003 poverty gap (\$/month) } \\
\hline & $\begin{array}{l}\text { Local Linear } \\
\text { (1) }\end{array}$ & $\begin{array}{c}\text { Quadratic } \\
\text { (2) }\end{array}$ & $\begin{array}{c}\text { Local Linear } \\
\text { (3) }\end{array}$ & $\begin{array}{c}\text { Quadratic } \\
\text { (4) }\end{array}$ \\
\hline \multicolumn{5}{|l|}{ All provinces } \\
\hline Eligible & $\begin{array}{l}1.67 \\
(2.13)\end{array}$ & $\begin{array}{c}1.52 \\
(3.68)\end{array}$ & $\begin{array}{c}2.11 \\
(3.12)\end{array}$ & $\begin{array}{c}4.13 \\
(5.49)\end{array}$ \\
\hline \multicolumn{5}{|c|}{ Batch A province only (program active in 2003) } \\
\hline Eligible & $\begin{array}{c}0.52 \\
(1.16)\end{array}$ & $\begin{array}{l}0.013 \\
(2.03)\end{array}$ & $\begin{array}{c}0.84 \\
(1.72)\end{array}$ & $\begin{array}{c}1.26 \\
(3.08)\end{array}$ \\
\hline Controls & Yes & Yes & Yes & Yes \\
\hline Observations & 399 & 399 & 399 & 399 \\
\hline
\end{tabular}

The table reports results of the Regression Discontinuity design described in Section 2. The running variable is the distance between the municipality's poverty rank and the provinical eligibility threshold. Local linear regressions use triangular kernel weights with a bandwidth of 6 ranks. Local linear regressions control for flexible trends of the running variable on each side of the eligibility threshold and use triangular kernel weights with a bandwidth of 6 ranks. Quadratic regressions control for flexible quadratic trends of the running variable on both sides of the threshold. ${ }^{*},{ }^{* *} * * *$ denote statistical significance of the underlying coefficient at the $10 \%, 5 \%$ and $1 \%$ levels. Standard errors are clustered at the province level. All specifications include the control variables shown in Table 2 and year fixed effects. 


\section{Table 13: Robustness Test for Discontinuities at Pseudo-Thresholds}

\begin{tabular}{|c|c|c|c|c|}
\hline \multicolumn{5}{|c|}{ "Dependent variable: Total casualties (entire program period) } \\
\hline & \multicolumn{2}{|c|}{ Poisson QMLE } & \multicolumn{2}{|c|}{ OLS } \\
\hline & $\begin{array}{c}\text { Local Linear } \\
(1)\end{array}$ & $\begin{array}{c}\text { Quadratic } \\
(2)\end{array}$ & $\begin{array}{c}\text { Local Linear } \\
(3)\end{array}$ & $\begin{array}{c}\text { Quadratic } \\
(4)\end{array}$ \\
\hline \multicolumn{5}{|c|}{ Pseudo-threshold at -2 (median of eligible municipalities) } \\
\hline \multirow[t]{2}{*}{ Eligible } & 0.0322 & 0.0148 & 0.0416 & 0.0424 \\
\hline & $(0.0650)$ & $(0.187)$ & $(0.0949)$ & $(0.226)$ \\
\hline \multicolumn{5}{|c|}{ Pseudo-threshold at 3 (median of ineligible municipalities) } \\
\hline \multirow[t]{2}{*}{ Eligible } & -0.0888 & -0.0460 & 0.0031 & -0.0304 \\
\hline & $(0.295)$ & $(0.0339)$ & $(0.0276)$ & $(0.0308)$ \\
\hline Observations & 14364 & 14364 & 14364 & 14364 \\
\hline Municipalities & 399 & 399 & 399 & 399 \\
\hline
\end{tabular}

The table reports results of the Regression Discontinuity design described in Section 2. The running variable is the distance between the municipality's poverty rank and pseudo-thresholds at -2.5 and 2.5 poverty ranks (the respectivemedians for eligible and ineligible municipalities). Local linear regressions control for flexible trends of the running variable on each side of the pseudo-threshold and use triangular kernel weights with a bandwidth of 6 ranks. Quadratic regressions control for flexible quadratic trends of the running variable on both sides of the pseudo-threshold. For poisson models, reported values are marginal effects. ${ }^{*},{ }^{* * * * *}$ denote statistical significance of the underlying coefficient at the $10 \%, 5 \%$ and $1 \%$ levels. Standard errors are clustered at the province level. All specifications include year fixed effects. 